\title{
Emission Patterns of Esters and Their Precursors Throughout Ripening and Senescence in 'Redchief Delicious' Apple Fruit and Implications Regarding Biosynthesis and Aroma Perception
}

\author{
Alejandra Ferenczi \\ Ministry of Livestock, Agriculture, and Fisheries, Department of Biosecurity, 1476 Montevideo, \\ 11200, Uruguay \\ Nobuko Sugimoto and Randolph M. Beaudry \\ Department of Horticulture, Michigan State University, 1066 Bogue Street, East Lansing, MI \\ 48824
}

\begin{abstract}
AdDitional INDEX words. AAT, alcohol acyl transferase, sensory, citramalate, fatty acid, Km, Vmax
Abstract. The volatile profile of 'Redchief Delicious' apple (Malus $\times$ domestica Borkh.) fruit was evaluated at 18 time points from 3 weeks before to 8 weeks after onset of autocatalytic ethylene production to capture the dynamics associated with development from mature green to senescent fruit. Minor amounts of ester production began several days before the onset of ethylene production. Ester production rose rapidly as internal ethylene levels increased beyond $22 \mathrm{nmol} \cdot \mathrm{L}^{-1}\left(0.5 \mu \mathrm{L} \cdot \mathbf{L}^{-1}\right)$. Peak ester production roughly coincided with maximum ethylene synthesis, declining thereafter. Ester production was further evaluated according to the acid- (alkanoate) and alcohol- (alkyl) derived portions of the ester. The maximum rate of production for a given ester tended to occur later in development as the chain length of the alcohol-derived portion declined. The production rate for many esters paralleled the rate of emanation of their respective alcohol substrates, suggesting that availability of the alcohols limits ester production more than availability of the acid substrates. Combining production rates with sensory descriptors and human sensitivity to individual volatiles permitted approximations of aroma sensations likely engendered by the fruit throughout ripening. Overripe and alcoholic sensations are predicted to increase 2 weeks after the initiation of ripening in response to an increase in the production of ethyl esters. Acetate esters predominated, comprising $50 \%$ to $80 \%$ of esters throughout maturation and ripening, indicating that the substrate acetyl-CoA may be at saturating levels for alcohol acyl transferase (AAT) at the final step of ester formation. Acetate feeding did not enhance ester production, although label from ${ }^{13} \mathrm{C}$-acetate was extensively incorporated into esters. The data are consistent with the action of multiple AAT isozymes differing in activity and substrate preference. Incorporation of labeled ${ }^{13} \mathrm{C}$-acetate into precursors of esters, alcohols, and acids, reflected ester biosynthesis via 1- and 2-carbon chain elongation pathways in ripening 'Redchief Delicious' apple fruit.
\end{abstract}

Flavor is an important parameter of fruit quality that influences consumer acceptability. Volatile aroma compounds comprise $\approx 75 \%$ of what is perceived as flavor in food (Murphy et al., 1977) and contribute to the perceived quality in all fresh fruits. In apples (Malus $\times$ domestica), more than 300 volatile compounds (esters, alcohols, aldehydes, terpenes, and hydrocarbons) have been identified (Dimick and Hoskin, 1983; Flath et al., 1967). Of these volatiles, esters are the most important class in terms of quantity and perception (Dixon and Hewett, 2000b; Fellman et al., 2000). Of the dozens of esters produced by apple, butyl acetate, hexyl acetate, 2-methylbutyl acetate, hexyl 2methylbutanoate, and ethyl 2-methyl butanoate are considered to

Received for publication 1 Mar. 2021. Accepted for publication 7 Apr. 2021. Published online 23 June 2021

R.M.B. acknowledges support from Michigan AgBioResearch and the U.S. Department of Agriculture National Institute of Food and Agriculture, Hatch project MICL002688. We thank Philip Engelgau for his insights, suggestions, and critical analysis of this paper.

R.M.B. is the corresponding author. E-mail: beaudry@msu.edu.

This is an open access article distributed under the CC BY-NC-ND license (https://creativecommons.org/licenses/by-nc-nd/4.0/). be most important for aroma perception, depending on the cultivar (Espino-Díaz et al., 2016; Yan et al., 2020).

Ester biosynthesis is affected by cultivar (Dixon and Hewett, 2000a), growing conditions (Miller et al., 1998), fruit maturity (Fellman and Mattheis, 1995; Song and Bangerth, 1994), storage conditions (Patterson, et al., 1974), and postharvest treatments (Ferenczi et al., 2006; Mir and Beaudry, 1999). It is known that aroma biosynthesis in fruits is correlated with ethylene synthesis and action in climacteric fruit (Brown et al., 1966; Dirinck et al., 1989; Mattheis et al., 1991; Song and Bangerth, 1996; Tressl and Drawert, 1973). However, the developmentally dependent progression of the full spectrum of volatiles and their levels is not well described, and their linkage with concomitant events, such as the climacteric rise in fruit respiration, is not fully understood (Fellman et al., 2000).

Esters are composed of either straight- or branched-chain alkyl (alcohol-derived) and alkanoate (acid-derived) groups. The esters in fruits are formed by the condensation of CoA derivatives of carboxylic acids and free alcohols in a reaction catalyzed by various alcohol acyltransferase [AAT (EC2.3.1.84)] enzymes (Ueda and Ogata, 1977). In apple, the carbon chain-length of the alcohol portion of the ester usually varies between 1- and 6-carbons and the 
acid portion has a typical chain-length from 2- to 8-carbons and both the alkyl and alkanoate moieties can be straight or branched. The branched-chain esters are derived from the pathways associated with branched-chain amino acid biosynthesis via 1-carbon (1-C) fatty acid biosynthesis (FAB) (Kroumova and Wagner, 2003; Sugimoto et al., 2011, 2015, 2021) and degradation (Nursten, 1970; Pérez et al., 2002; Tressl and Drawert, 1973; Wyllie et al., 1995). Straight-chain fatty acids are believed to be derived from fatty acid metabolism via degradative (Bartley et al., 1985; Brackmann et al., 1993; Fellman et al., 2000; Nursten, 1970; Rowan et al., 1996, 1999) and synthetic (Contreras and Beaudry, 2013, Contreras et al., 2015; Kroumova and Wagner, 2003; Schiller et al., 2015; Sugimoto et al., 2021; Tan and Bangerth, 2001) processes. Although considerable progress has been made in isolating and identifying a large number of volatile compounds contributing to plant aromas, less work has been done on elucidating the mechanisms of their formation.

Ester biosynthesis shifts in amount and composition throughout ripening and senescence (Drawert et al., 1969; Williams and Knee, 1977). The ester profile at any given time is influenced by substrate availability (Knee and Hatfield, 1981; Wyllie and Fellman, 2000), AAT expression (Aharoni et al., 2000; Jayanty et al., 2002; Schafer et al., 2007), and the activity and specificity of AAT isozymes (Olias et al., 1995; Pérez et al., 1993, 1996). The relative importance of each factor might change as ripening progresses, but little is known about the extent of influence throughout fruit ripening and senescence. Even less is understood about the collective influence of these factors on aroma perception.

Members of the $A A T$ gene family have been characterized in a number of fruit species, including apple, strawberry (Fragaria $\times$ ananassa Duchesne), melon (Cucumis melo L. var. cantalupensis Naud.), and banana (Musa L. sp., AAA group, Cavendish subgroup, 'Valery') (Aharoni et al., 2000; Harada et al., 1985; Jayanty et al., 2002; Souleyre et al., 2005; Yahyaoui et al., 2002). Several AAT isozymes have been studied and were determined to use a broad range of precursors, although they do exhibit marked substrate preferences.

In apple, although there may be 17 or more $A A T$ genes, only two AAT isozymes, MdAAT1 (also known as MpAAT1) and MdAAT2 have been characterized to any appreciable extent (Dunemann et al., 2012; Li et al., 2006; Souleyre et al., 2005). Of these, only MdAAT1 has been characterized at the enzyme level (Souleyre et al., 2005). MdAAT1 has the highest rate of reaction with 1-hexanol compared with other alcohols when 1hexanol levels are high in the presence of saturating levels of acetyl-CoA. However, at low levels of alcohol substrates, 2methyl-1-butanol results in higher rates of ester production because of its much lower $\mathrm{K}_{\mathrm{m}}$. Thus, the substrate specificity of a single AAT isozyme will affect yields of individual esters as enzyme and substrate levels vary. Further, although the ester profile can be altered by the simultaneous operation of more than one AAT isozyme (Beekwilder et al., 2004; CumplidoLaso et al., 2012), conclusive evidence for this is lacking in apple.

The aim of this research was to characterize patterns in the biosynthesis of esters and their precursors during ripening and senescence of 'Redchief Delicious' apple with a level of detail not previously attempted to better understand ester dynamics and the relationship between precursor and product and to use production rates of these odor active volatiles to predict their influence on changes in aroma perception during ripening and senescence. In addition, we wanted to determine if production rates of individual esters were in agreement with available kinetic analyses of MdAAT1 and use these data to infer whether changes in AAT substrate specificity take place during apple fruit ripening, which would indicate multiple AAT isozymes impact apple aroma. Further, we wished to determine whether esters were synthesized in 'Redchief Delicious' apples via the newly described citramalate pathway, which uses 1-C FAB, and/ or via the relatively more fully characterized 2-C FAB pathway (Kroumova and Wagner, 2003; Risso et al., 2008; Sugimoto et al., 2011, 2015, 2021; Xu et al., 2004) by evaluating the incorporation of acetic acid as a native compound and as 1-, 2-, and 1,2- $\left[{ }^{13} \mathrm{C}_{2}\right]$ isotopologs (Sugimoto et al., 2021).

\section{Materials and Methods}

\section{Expt. 1. Developmentally dependent volatile analysis}

Plant material. 'Redchief Delicious' apples were harvested every 3 to $4 \mathrm{~d}$ at the Michigan State University Horticultural Teaching and Research Center (HTREC), East Lansing, MI, beginning from 8 Sept. 2000 (day 0) until fruit were considered to have initiated ripening based on internal ethylene content (IEC), which was considered to occur when the IEC rose above $9 \mathrm{nmol} \cdot \mathrm{L}^{-1}\left(0.2 \mu \mathrm{L} \cdot \mathrm{L}^{-1}\right)$ on day 25 (3 Oct. 2000). On each date, fruit were brought into the laboratory and held overnight to equilibrate at room temperature $\left(20 \pm 1{ }^{\circ} \mathrm{C}\right)$ before analysis. All fruit remaining on the tree were harvested on day 25 . These fruits were held at room temperature $\left(20 \pm 1^{\circ} \mathrm{C}\right)$ and examined every 3 to $4 \mathrm{~d}$ until the end of the study (day 71). In all, 18 different stages of development ranging from mature, unripe through senescent, were measured.

On each evaluation date, 20 fruit were randomly chosen for internal ethylene measurement and five fruit nearest to the median were selected for subsequent respiratory $\mathrm{CO}_{2}$ and volatile analysis.

INTERNAL ETHYLENE MEASUREMENT. The IEC was determined by withdrawing a 1-mL gas sample from the interior of apples and subjecting the gas sample to gas chromatographic (GC) analysis (Carle Series 400 AGC; Hach Co., Loveland, CO) as previously described (Mir et al., 2001).

Respiration MEASUREMENT. Respiratory $\mathrm{CO}_{2}$ production was measured on the five fruit having an IEC nearest the sample median. Apples were placed singly into 1-L Teflon chambers (Savillex Corp., Minnetonka, MN) and maintained in the chambers for $\approx 3 \mathrm{~h}$ at $22^{\circ} \mathrm{C}$ by ventilating with pure air at a known rate to reach steady-state. Flow rates differed slightly for each chamber, but averaged $\approx 25 \mathrm{~mL} \cdot \mathrm{min}^{-1}$. The air stream exited the chamber through a "T" fitted with a half-hole, Teflon-lined septum (Supelco Co., Bellefonte, PA) used as a sampling port. $\mathrm{CO}_{2}$ in the outflow was measured on a $0.1-\mathrm{mL}$ gas sample taken through the exit line septum using a $0.5-\mathrm{mL}$ plastic syringe. The gas sample was injected into an infrared gas analyzer (model 225-MK3; Analytical Development Co., Hoddesdon, England) operated in a flow-through mode with $\mathrm{N}_{2}$ as the carrier gas and a flow rate of $100 \mathrm{~mL} \cdot \mathrm{min}^{-1}$. The $\mathrm{CO}_{2}$ concentration was calculated using a certified standard (Matheson Gas Products, Chicago, IL) containing $5 \% \mathrm{CO}_{2}$ by volume diluted 10 -fold to create a $0.5 \%(0.5 \mathrm{kPa})$ standard, which was closer to the concentrations found in the exit lines of the respirometers. The difference between inlet and exit line $\mathrm{CO}_{2}$ concentrations was used to calculate the rate of respiration. 
Volatile analysis. Volatile organic compounds were sampled using a 1-cm-long solid-phase microextraction (SPME) fiber coated with a film thickness of $65 \mu \mathrm{m}$ of polydimethylsiloxane/divinylbenzene (Supelco) inserted into the chamber exit line sampling port for $5 \mathrm{~min}$. One chamber with no fruit was used as a blank. After sorption, the SPME fiber was immediately transferred to a GC (HP-6890; Agilent Technologies, Santa Clara, CA) splitless injection port at $230^{\circ} \mathrm{C}$ and desorbed for 5 $\mathrm{min}$. Volatiles were concentrated at the head of the column with a liquid nitrogen cold trap, made by submerging the head of the column in a pool of liquid nitrogen, and released by removal of the liquid nitrogen. The GC was equipped with a mass spectrometer (MS) detector (Pegasus II; LECO, St. Joseph, MI). Headspace compounds were separated using a $15-\mathrm{m}$-long capillary column (Supelcowax, Supelco) with a 0.1-mm i.d. and $0.25-\mu \mathrm{m}$ film thickness. Conditions of GC separation and mass spectrometry analysis were as previously described (Song et al., 1997).

Identification of compounds was by comparison of the deconvoluted mass spectrum with authenticated reference standards and/or with spectra in the National Institute for Standard and Technology mass spectrum library (version 05). Volatile compounds (Supplemental Table 1) were quantified by calibrating with a known amount of an authenticated, high-purity standard mixture of 13 alcohols, aldehydes, and esters as previously described (Song et al., 1997). Where no standard was available, volatiles were quantified by estimation of the instrument response factor based on the Kovats index for the compound of interest (Bartelt, 1997). To develop this relationship, 41 compounds were used, having Kovats numbers ranging from 440 to 1387 (Supplemental Fig. 1).

For apple fruit, there were five replicate samples on each analysis date. In all, 36 esters, five alcohols, and five acids were identified and quantified by GC/MS with retention times varying between 55 and $215 \mathrm{~s}$. The production rate (micromoles per kilogram per hour) was calculated for all compounds. Total ester production throughout ripening (micromoles per kilogram) was calculated by integrating the production rate across time for the $71 \mathrm{~d}$ of the study. The concentration of the alcohols 1-butanol,

Table 1. Abundant and odor active esters and alcohols detected during the ripening of 'Redchief Delicious' apple fruit ripened at $20^{\circ} \mathrm{C}$ in air, their sensory descriptors according to Dimick and Hoskin (1983), Espino-Díaz et al. (2016), The Good Scents Company (2021), and Yan et al. (2020), the descriptor categories chosen for characterizing human perception in this study [Fruity/floral (F), overripe/ cheesy/fatty/off-flavor (O), grassy/green (G), alcoholic/winey (A), sweet/ether/solvent/chemical (S)], and human odor thresholds according to Espino-Díaz et al. (2016) and Leffingwell and Associates (2021).

\begin{tabular}{|c|c|c|c|}
\hline Compound & Common descriptors & Categories & $\begin{array}{l}\text { Avg odor threshold } \\
\text { in water }\left(\mu \mathrm{g} \cdot \mathrm{L}^{-1}\right)\end{array}$ \\
\hline \multicolumn{4}{|l|}{$\begin{array}{l}\text { Alcohols } \\
\end{array}$} \\
\hline Ethanol & Sweet-ethereal, mild, wine, whiskey & $\mathrm{A}, \mathrm{S}$ & 55 \\
\hline 1-Propanol & Alcoholic-nauseating, sweet odor & $\mathrm{O}, \mathrm{A}, \mathrm{S}$ & 9 \\
\hline 2-Methylpropanol & Mild, chemical, sweet, harsh when dilute & $\mathrm{S}$ & 22 \\
\hline 1-Butanol & "Fusel"-like odor, alcoholic, solvent-like, sweet, banana & $\mathrm{F}, \mathrm{A}, \mathrm{S}$ & 0.5 \\
\hline 2-Methylbutanol & Highly diluted-pleasant, fruity-winey spicy & $\mathrm{F}, \mathrm{A}$ & 0.025 \\
\hline 1-Hexanol & Very penetrating, fatty-green grassy odor & $\mathrm{O}, \mathrm{G}$ & 1.5 \\
\hline \multicolumn{4}{|l|}{ Esters } \\
\hline Ethyl acetate & Pleasant, ethereal-fruity, brandy-like odor & $\mathrm{F}, \mathrm{A}, \mathrm{S}$ & 9.25 \\
\hline Ethyl propanoate & $\begin{array}{l}\text { Ethereal, fruity-rum-like odor (correlated with overripe/cheesy } \\
\text { odor) }\end{array}$ & $\mathrm{F}, \mathrm{O}, \mathrm{A}, \mathrm{S}$ & 0.01 \\
\hline Ethyl butanoate & $\begin{array}{l}\text { Powerful, ethereal-fruity odor, banana, pineapple (correlated } \\
\text { with overripe/cheesy odor) }\end{array}$ & $\mathrm{F}, \mathrm{O}, \mathrm{G}, \mathrm{S}$ & 0.001 \\
\hline Ethyl 2-methylbutyrate & $\begin{array}{l}\text { Powerful diffusive, green-fruity, pungent odor (correlated with } \\
\text { overripe/cheesy odor) }\end{array}$ & $\mathrm{F}, \mathrm{O}, \mathrm{G}$ & 0.0006 \\
\hline Ethyl pentanoate & Fruity, sweet & $\mathrm{F}, \mathrm{S}$ & 0.003 \\
\hline Ethyl hexanoate & Fruity, waxy, fatty, wine & $\mathrm{F}, \mathrm{O}, \mathrm{A}$ & 0.001 \\
\hline Propyl acetate & Fruity, pear & $\mathrm{F}$ & 1.1 \\
\hline Propyl propanoate & Fruity, sherry, ethereal & $\mathrm{F}, \mathrm{A}, \mathrm{S}$ & 0.057 \\
\hline Propyl butanoate & Fruity, sweet, rancid & $\mathrm{F}, \mathrm{O}, \mathrm{S}$ & 0.07 \\
\hline 2-Methylpropyl acetate & Fruity, apple pear & $\mathrm{F}$ & 0.065 \\
\hline Butyl acetate & Very diffusive, ethereal-fruity, pungent, pear odor, banana & $\mathrm{F}, \mathrm{S}$ & 0.066 \\
\hline Butyl propanoate & Fruity, sweet, & $\mathrm{F}, \mathrm{S}$ & 0.112 \\
\hline Butyl butanoate & Rotten apple & $\mathrm{F}, \mathrm{O}$ & 0.1 \\
\hline Butyl hexanoate & Acid, rancid, fruity, grass & $\mathrm{F}, \mathrm{O}, \mathrm{G}$ & 0.7 \\
\hline Butyl 2-methylbutanoate & Fruity & $\mathrm{F}$ & 0.017 \\
\hline 2-Methylbutyl acetate & Sweet-fruity, banana, pear-like & $\mathrm{F}, \mathrm{S}$ & 0.008 \\
\hline Pentyl acetate & Apple, fruity, banana & $\mathrm{F}$ & 0.024 \\
\hline Hexyl acetate & Sweet, fruity, slightly floral & $\mathrm{F}, \mathrm{S}$ & 0.002 \\
\hline Hexyl propanoate & Fruity, overripe, rotting fruit & $\mathrm{F}, \mathrm{O}$ & 0.001 \\
\hline Hexyl butanoate & Fruity, fragrance & $\mathrm{F}$ & 0.25 \\
\hline Hexyl hexanoate & Fruity, green, wine & $\mathrm{F}, \mathrm{G}, \mathrm{A}$ & 1.8 \\
\hline
\end{tabular}




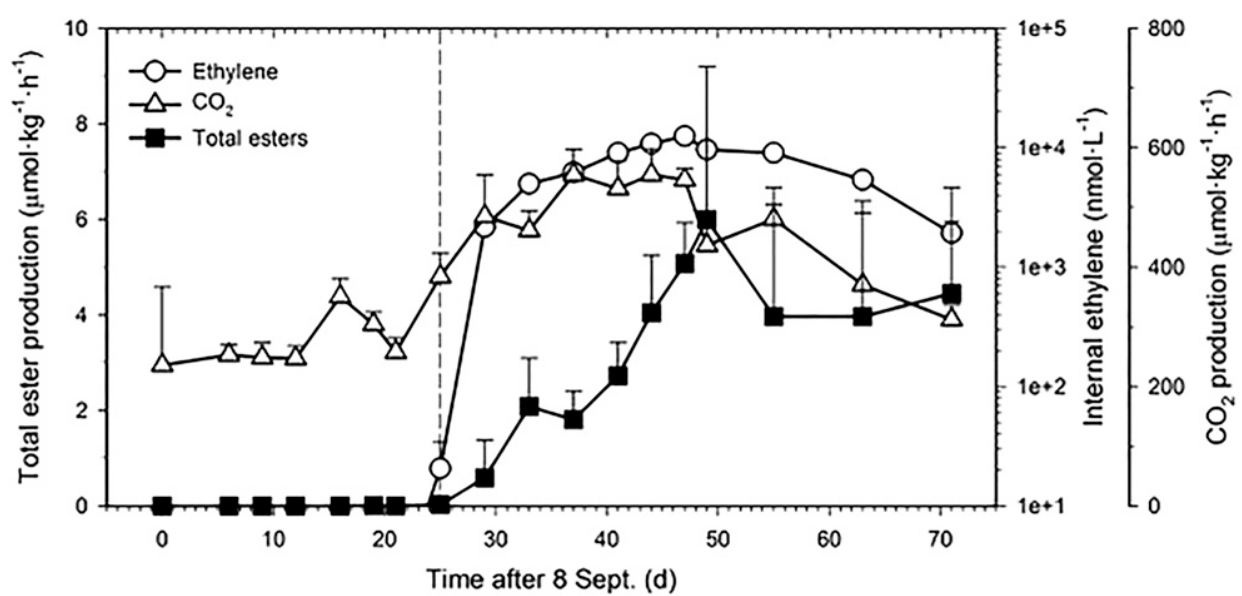

Fig. 1. Ontogeny of total esters, ethylene, and respiration $\left(\mathrm{CO}_{2}\right.$ production) during ripening and senescence of 'Redchief Delicious' apples at room temperature $\left(20^{\circ} \mathrm{C}\right)$. The volatile profile of apple fruit was tracked from 3 weeks before 8 weeks after the onset of autocatalytic ethylene production (indicated by dashed vertical line). Each symbol represents the average of five replications \pm SD. 2-methyl-1-butanol, and 1-hexanol in the headspace of the respirometer was used to estimate the tissue concentrations of the alcohols using the Henry's coefficient for each alcohol (Knee and Hatfield, 1976, 1981) and diffusion was assumed to be Fickian in nature (Knee, 1991; Knee and Hatfield, 1976). Statistical analysis of production rates of volatiles primarily consisted of calculation of standard deviations for mean values. However, to characterize the pattern of production, additional analysis was performed. The pattern was evaluated for the presence of a shoulder to a peak, an elevated shoulder to a peak, or two peaks using $t$ tests $(P<0.05)$ by comparing the following: 1$)$ the maximum with the apparent shoulder/second peak, 2) the maximum with the trough between the shoulder/second peak and the maximum, and 3) the trough with the shoulder/second peak. If the values for the maximum and the shoulder/second peak both differed from any intervening trough value, the pattern was considered to have two peaks (or two periods of elevated production with an intervening trough). If the maximum value differed from the trough value, but did not differ from the shoulder/second peak and the shoulder/second peak did not differ from the trough, the pattern was considered as having an elevated shoulder. If the maximum value differed from both the shoulder/second peak and the trough and the trough and the shoulder/second peak were similar, the pattern was considered as having a shoulder to the maxima peak.

The impact of esters produced by 'Redchief Delicious' apples on aroma perception was predicted using semiquantitative means. To create this estimate, esters and alcohols for which sensory descriptors and human odor thresholds were available were identified among those quantified in this study (Table 1). Published odor thresholds for each compound (Espino-Díaz et al., 2016; Leffingwell and Associates, 2021), expressed in micrograms per kilogram for water solutions were converted to micromoles per kilogram. Each compound was then categorized for its sensory impact into one or more of five categories: fruity/ floral $(F)$, overripe/cheesy/fatty/off-flavor $(\mathrm{O})$, grassy/green $(\mathrm{G})$, alcoholic/winey (A), or sweet/ether/solvent/chemical (S), based on published sensory descriptors (Dimick and Hoskin, 1983; Espino-Díaz et al., 2016; The Good Scents Company, 2021; Yan et al., 2020) and given a preliminary score of 1 for each category. When compounds had descriptors that fit multiple categories, the score in each category was uniformly reduced so that the sum of category scores for any one compound totaled to 1 . The revised category score for each compound was then multiplied by the rate of production of that compound and divided by its odor threshold to obtain a prediction of the sensory impact of that compound in arbitrary units of per second. Following this, the predicted sensory impacts for all compounds were totaled for each of the five aroma categories for each analysis date.

Kinetic anALYSIS OF VOLATILE SYNTHESIS. We attempted to determine whether the rates of synthesis of acetate esters were reflective of the kinetic data for AAT from Souleyre et al. (2005) for apple and whether these data could be used to infer the existence of AAT enzymes with substantially different kinetic properties. The published $\mathrm{K}_{\mathrm{m}}$ of MdAAT1 for the alcohol substrates of hexyl acetate, 2-methylbutyl acetate, and butyl acetate were 2.7, 1.1, and 7.4 mM, for 1-hexanol, 2-methyl-1-butanol, and 1-butanol, respectively, under conditions of saturating acetyl-CoA. These were coupled with estimates of the concentration of their respective alcohols and measurements of the production rates of the esters in this study to

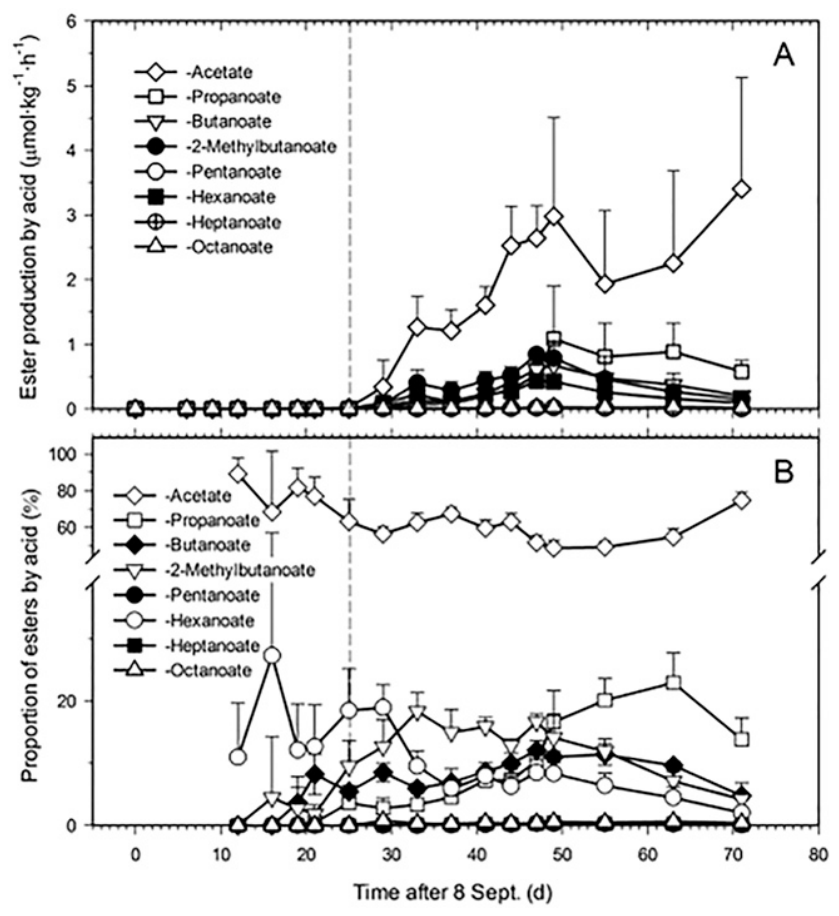

Fig. 2. Pattern of esters classed by the alkanoate (acid) moiety during ripening and senescence of 'Redchief Delicious' apple at room temperature $\left(20^{\circ} \mathrm{C}\right)$. The volatile profile was tracked from 3 weeks before 8 weeks after the onset of the ethylene climacteric (indicated by dashed vertical line). (A) Ester production classified by acid portions. (B) Ester proportions (\% of total alkanoate esters). Each symbol represents the average of five replications $\pm \mathrm{SD}$. 

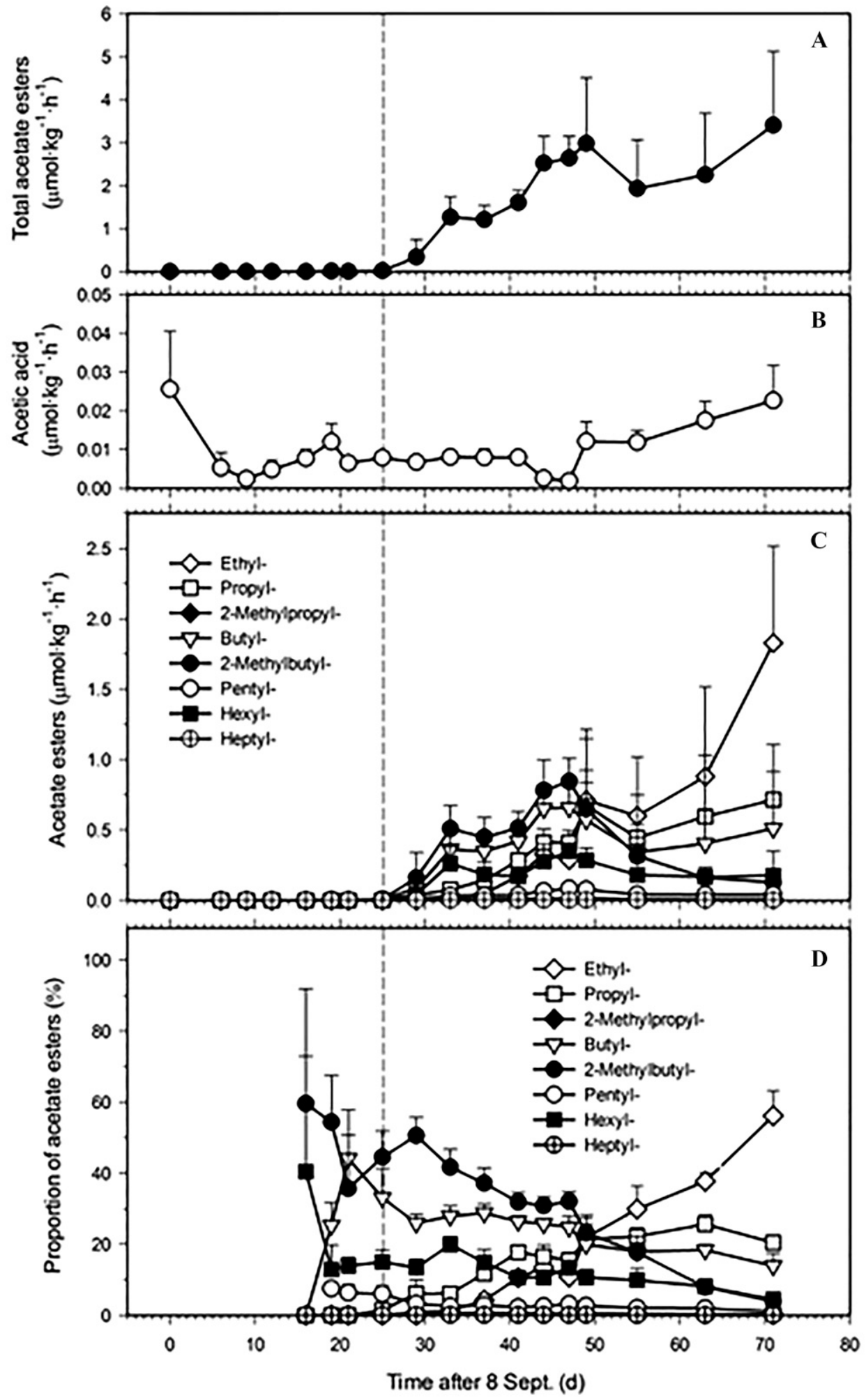

Fig. 3. Pattern of acetic acid and acetate ester emanations during ripening and senescence of 'Redchief Delicious' apple. The volatile profile was tracked for fruit held at $20^{\circ} \mathrm{C}$ from 3 weeks before 8 weeks after the onset of the ethylene climacteric (indicated by dashed vertical line). (A) Total acetate ester production. (B) Acetic acid production. (C) Acetate ester production classified by alcohol portions. (D) Ester proportions (\% of total acetate esters). Each symbol represents the average of five replications \pm SD. 

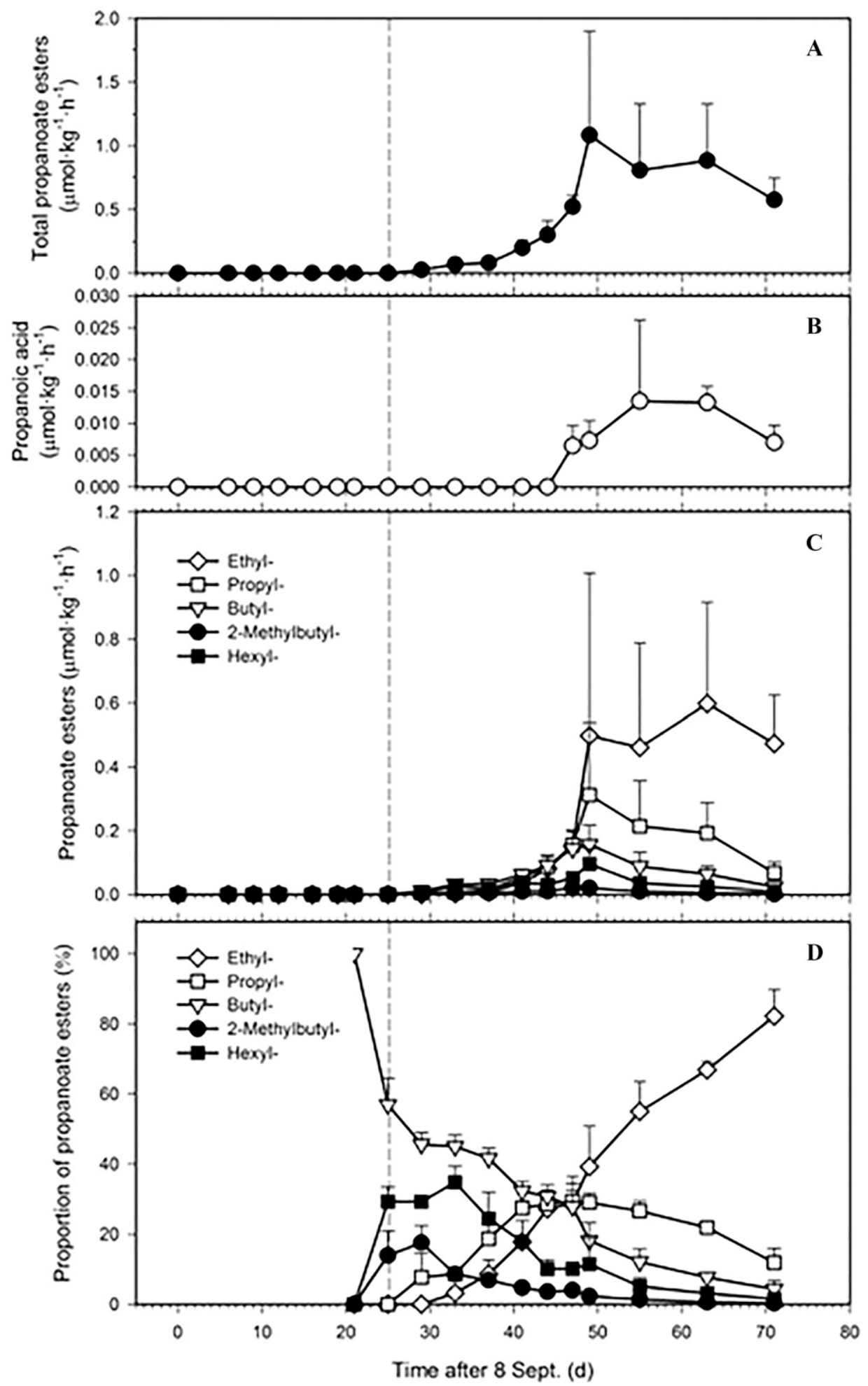

Fig. 4. Pattern of propanoate esters during ripening and senescence of 'Redchief Delicious' apple. The volatile profile was tracked for fruit held at $20{ }^{\circ} \mathrm{C}$ from 3 weeks before 8 weeks after the onset of the ethylene climacteric (indicated by dashed vertical line). (A) Total propanoate ester production. (B) Propanoic acid production. (C) Propanoate ester production classified by alcohol portions. (D) Ester proportions (\% of total propanoate esters). Each symbol represents the average of five replications $\pm \mathrm{SD}$. 


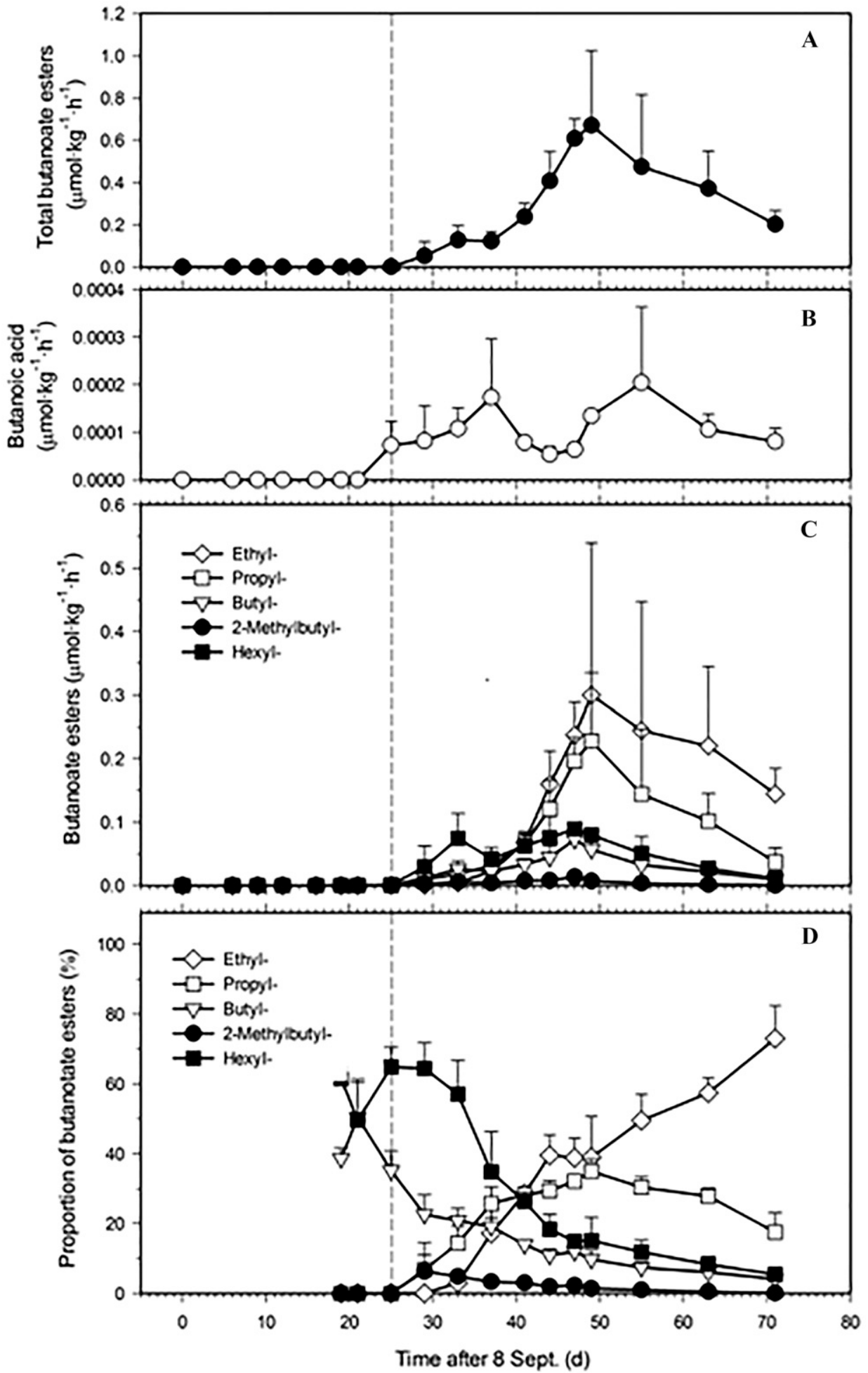

Fig. 5. Pattern of butanoate esters during ripening and senescence of 'Redchief Delicious' apple. The volatile profile was tracked for fruit held at $20^{\circ} \mathrm{C}$ from 3 weeks before 8 weeks after the onset of the ethylene climacteric (indicated by dashed vertical line). (A) Total butanoate ester production. (B) Butanoic acid production. (C) Butanoate ester production classified by alcohol portions. (D) Ester proportions (\% of total butanoate esters). Each symbol represents the average of five replications \pm SD. 

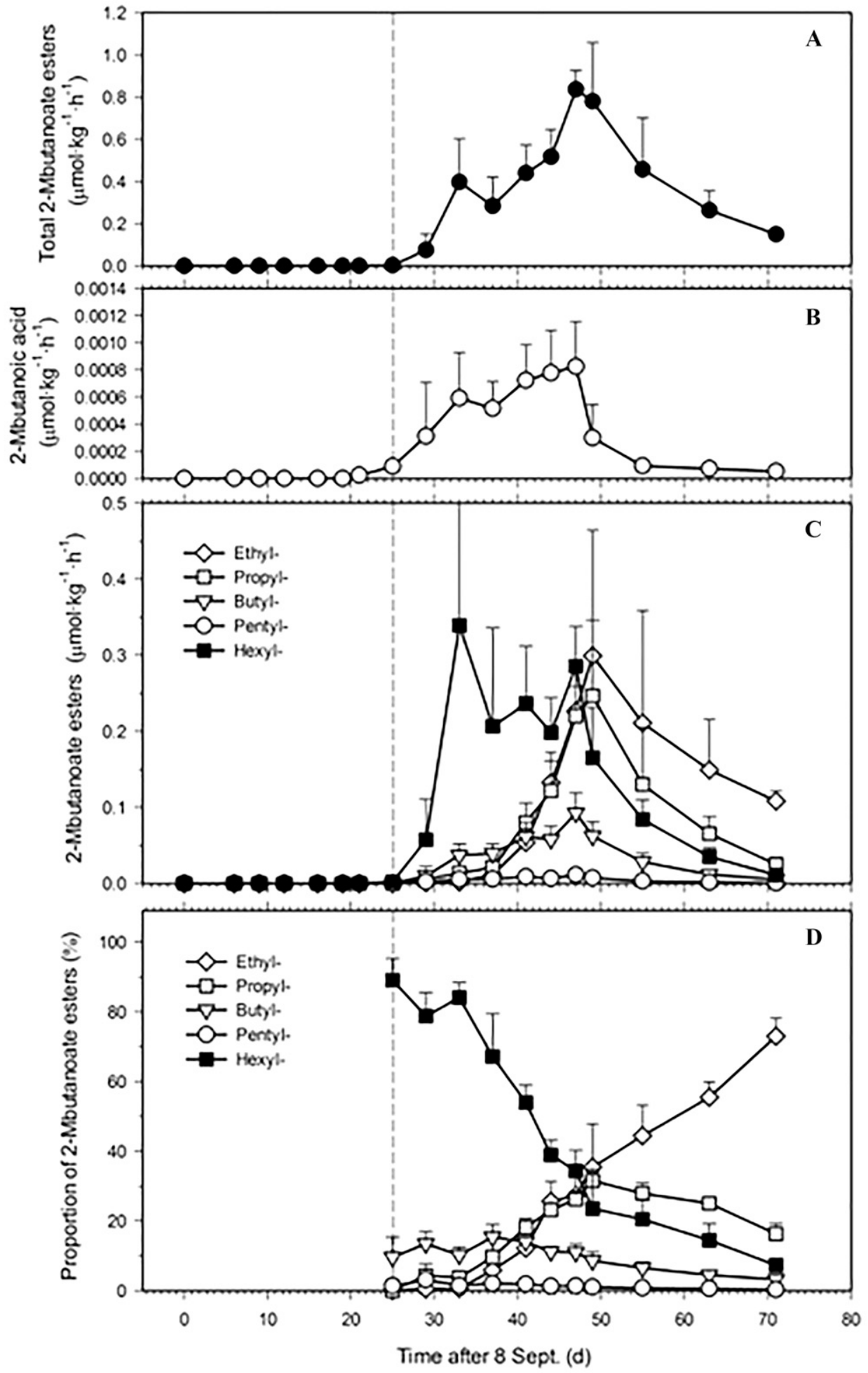

Fig. 6. Pattern of 2-methylbutanoate (2-Mbutanoate) esters during ripening and senescence of 'Redchief Delicious' apple. The volatile profile was tracked for fruit held at $20^{\circ} \mathrm{C}$ from 3 weeks before 8 weeks after the onset of the ethylene climacteric (indicated by dashed vertical line). (A) Total 2-methylbutanoate ester production. (B) 2-Methylbutanoic (2-Mbutanoic) acid production. (C) 2-Methylbutanoate ester production classified by alcohol portions. (D) Ester proportions ( $\%$ of total 2-methylbutanoate esters). Each symbol represents the average of five replications $\pm \mathrm{SD}$. 

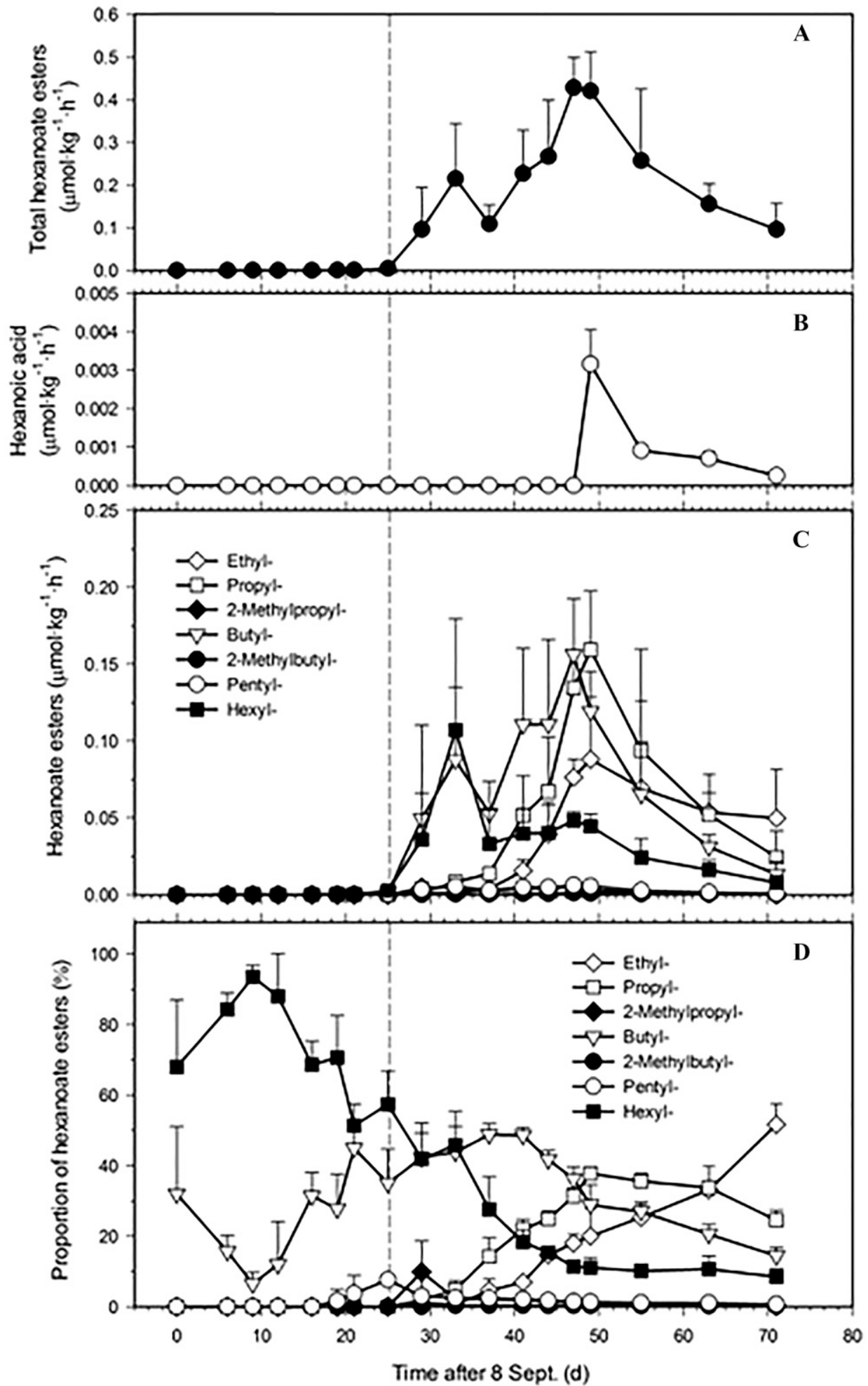

Fig. 7. Pattern of hexanoate esters during ripening and senescence of 'Redchief Delicious' apple. The volatile profile was tracked for fruit held at $20^{\circ} \mathrm{C}$ from 3 weeks before 8 weeks after the onset of the ethylene climacteric (indicated by dashed vertical line). (A) Total hexanoate ester production. (B) Hexanoic acid production. (C) Hexanoate ester production classified by alcohol portions. (D) Ester proportions (\% of total hexanoate esters). Each symbol represents the average of five replications \pm SD. 

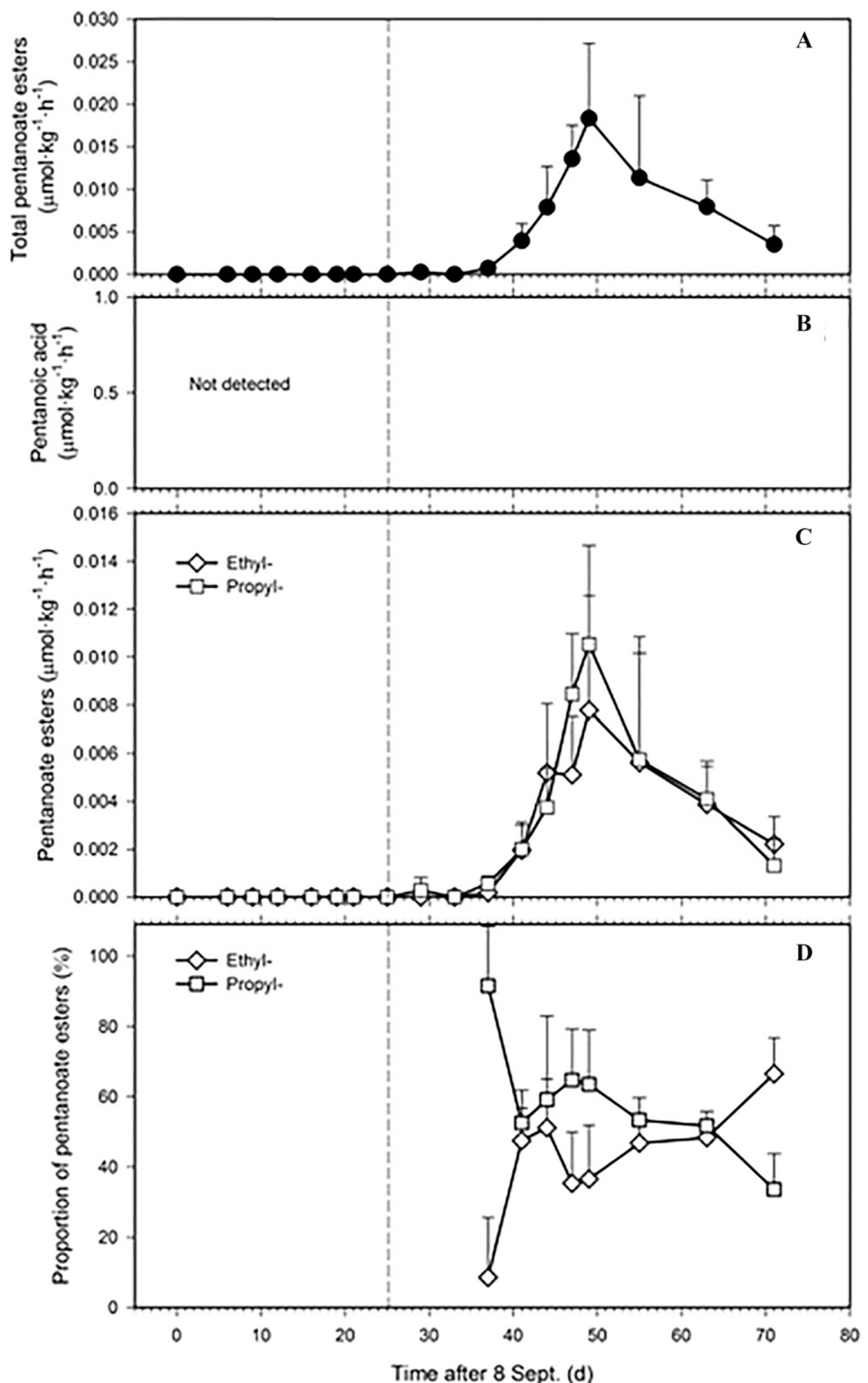

Fig. 8. Pattern of pentanoate esters during ripening and senescence of 'Redchief Delicious' apple. The volatile profile was tracked for fruit held at $20^{\circ} \mathrm{C}$ from 3 weeks before 8 weeks after the onset of the ethylene climacteric (indicated by dashed vertical line). (A) Total pentanoate ester production. (B) Pentanoic acid production. (C) Pentanoate ester production classified by alcohol portions. (D) Ester proportions (\% of total pentanoate esters). Each symbol represents the average of five replications $\pm \mathrm{SD}$. 

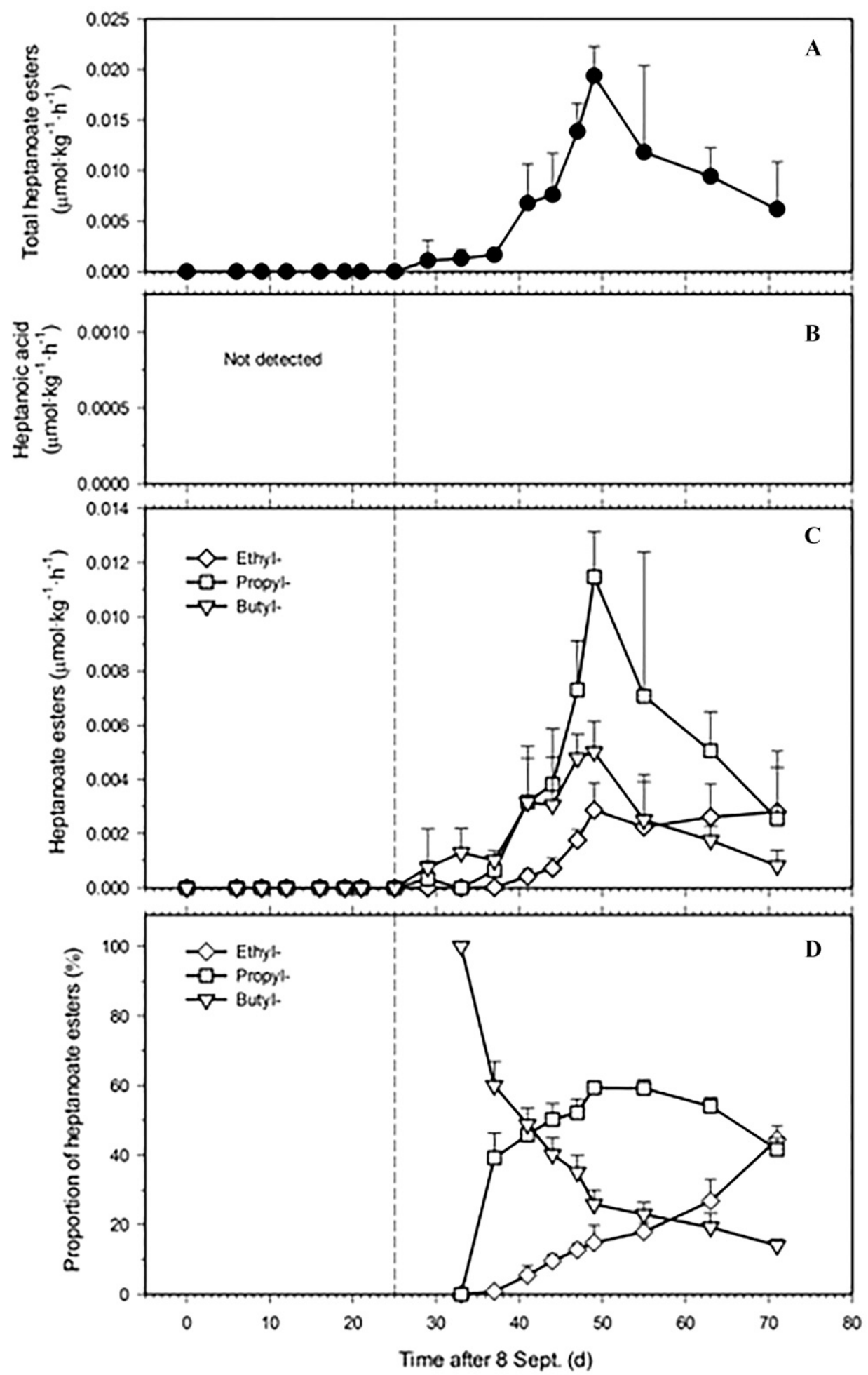

Fig. 9. Pattern of heptanoate esters during ripening and senescence of 'Redchief Delicious' apple. The volatile profile was tracked for fruit held at $20{ }^{\circ} \mathrm{C}$ from 3 weeks before 8 weeks after the onset of the ethylene climacteric (indicated by dashed vertical line). (A) Total heptanoate ester production. (B) Heptanoic acid production. (C) Heptanoate ester production classified by alcohol portions. (D) Ester proportions (\% of total heptanoate esters). Each symbol represents the average of five replications \pm SD. 


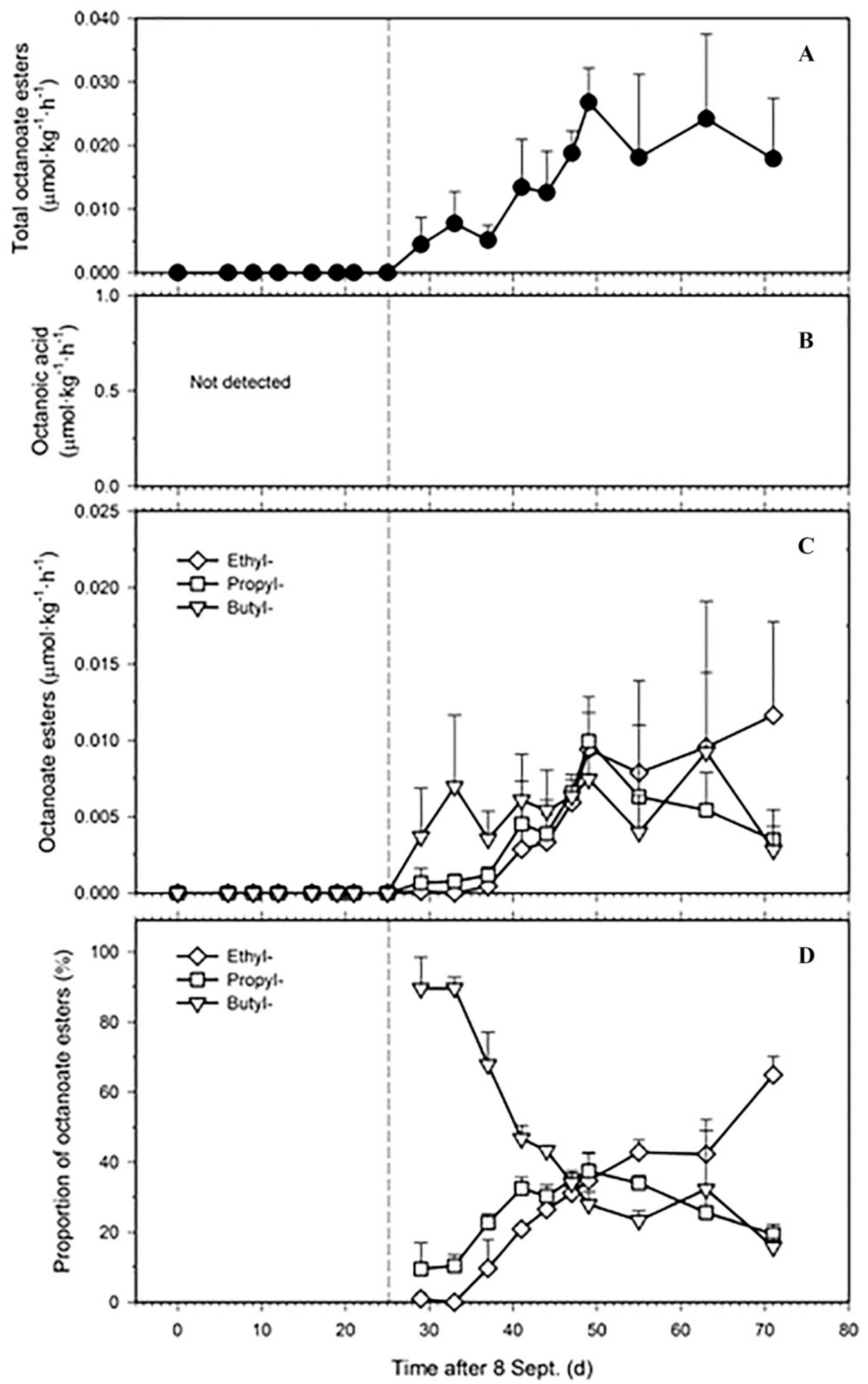

Fig. 10. Pattern of octanoate esters during ripening and senescence of 'Redchief Delicious' apple. The volatile profile was tracked for fruit held at $20^{\circ} \mathrm{C}$ from 3 weeks before 8 weeks after the onset of the ethylene climacteric (indicated by dashed vertical line). (A) Total octanoate ester production. (B) Octanoic acid production. (C) Octanoate ester production classified by alcohol portions. (D) Ester proportions (\% of total octanoate esters). Each symbol represents the average of five replications \pm SD. 

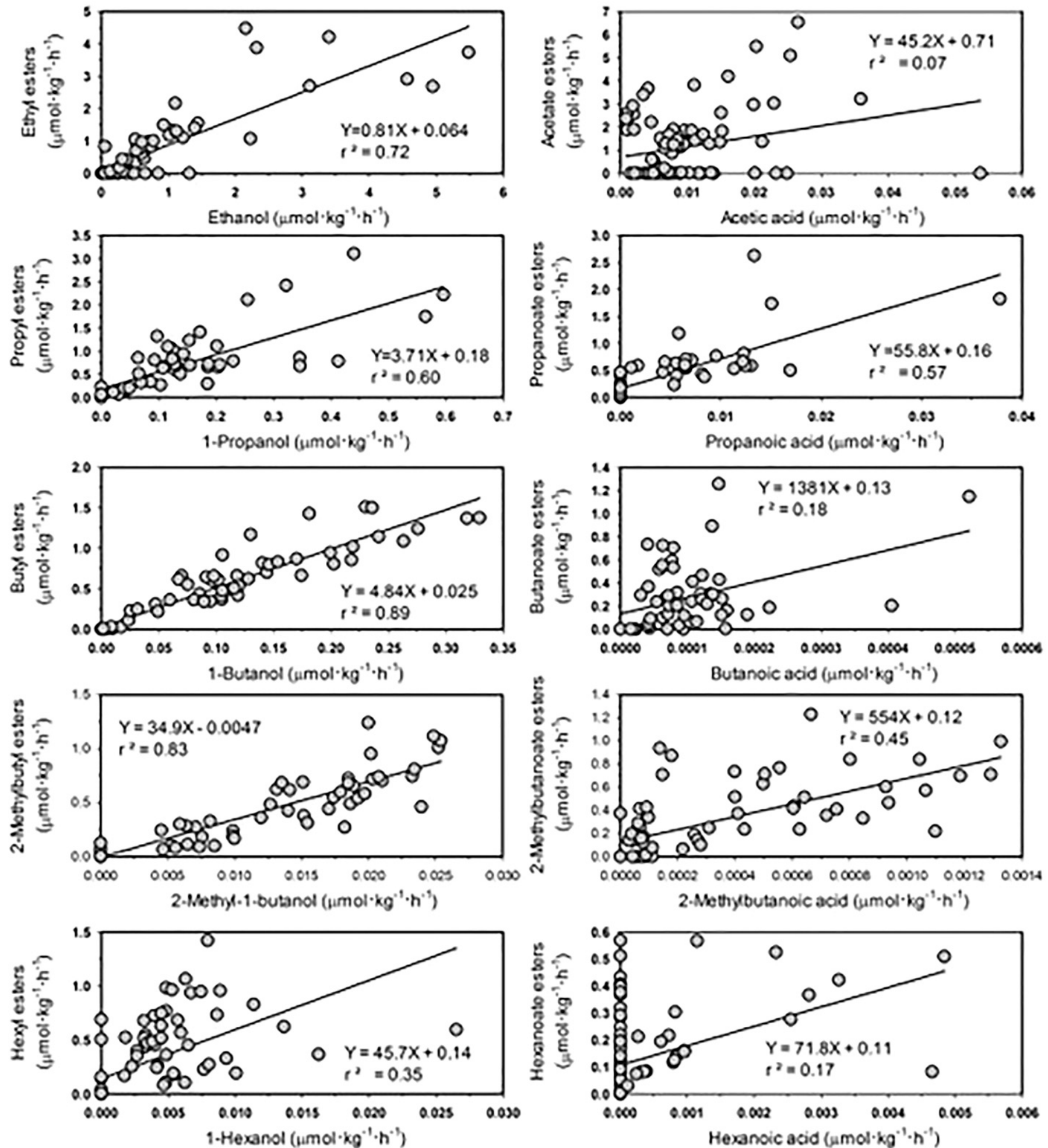

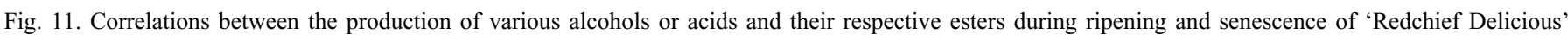
apple at room temperature $\left(20^{\circ} \mathrm{C}\right)$. The volatile profile was tracked from 3 weeks before 8 weeks after the onset of the ethylene climacteric. 
estimate the apparent $\mathrm{V}_{\max }$ for the three AAT reactions on a wholefruit basis according to the following equation:

$$
V_{\text {max }}=\text { Rate } \times\left(K_{m}+S\right) / K_{m}
$$

where Rate (micromoles per kilogram per hour) is the production rate of the specified ester on a whole-fruit basis; $K_{m}$ is the half-maximal concentration (millimolar) of the alcohol for the synthesis of the specified ester; and $S$ is the alcohol concentration (millimolar) in the fruit tissue. The value of $S$ was estimated from the headspace content of the respirometer using Henry's constant for the alcohols as previously described. The Henry's constants for 1-butanol, 2-methyl-1-butanol, and 1-hexanol were $1.117,0.662$, and $0.596 \mathrm{mmol} \cdot \mathrm{L}^{-1} \cdot \mathrm{Pa}^{-1}$, respectively, representing averages of four to five values as reported by Sander (2015). Alcohol concentrations were estimated once alcohols could be detected in the chamber headspace (day 33 to day 71).

The determination whether acetyl-CoA was at or near saturation required feeding apple tissues with exogenous acetate (see "Acetate and 13C-acetate incorporation"). If exogenously applied acetate was incorporated, but did not affect the total rate of ester production, it was assumed acetyl-CoA was at near saturating levels for AAT. We were unable to estimate the actual $\mathrm{V}_{\max }$ for AAT reactions because the concentration of the AAT protein in fruit tissues has not been determined; however, the estimates of the apparent $\mathrm{V}_{\max }$ as performed here should reflect the relative differences for these three alcohols published by Souleyre et al. (2005). Assuming the data met this standard, it was considered reasonable that by expressing the apparent $\mathrm{V}_{\max }$ on a whole-fruit basis, an increase or decrease in the apparent $\mathrm{V}_{\max }$ would be indicative of an increase or decrease in total AAT activity. Further, changes in the estimates of the apparent $\mathrm{V}_{\max }$ for the three alcohols relative to one another would be indicative of changes in complement of AAT isozymes.

\section{Expt. 2. Application of stable acetic acid isotopes}

Plant Material. 'Red Delicious' apples were harvested midOct. 2008 at the HTREC and allowed to ripen at room temperature until the IEC reached the equivalent ripening stage at day 49 for the fruit in Expt. 1. Peel tissue was used for incorporation studies because the peel constitutes the primary location of ester biosynthesis (Williams and Knee, 1977).

ACETATE AND ${ }^{13}$ C-ACETATE InCORPoration. Five filter paper discs (11.5-mm diameter) were placed on a glass slide and each was wetted with $\approx 20 \mu \mathrm{L}$ of $0.1 \mathrm{M}$ MES buffer, adjusted to $\mathrm{pH}$ 7, with or without methanol (MeOH, $20 \mathrm{~mm})$, and containing 20 $\mathrm{mm}$ of unlabeled or ${ }^{13} \mathrm{C}$-labeled acetic acid. $\mathrm{MeOH}$ was added to the MES solution to enhance the synthesis of methyl esters, which are normally present at extremely low levels in apple fruit (Sugimoto et al., 2015), and the labeled methyl esters could be considered largely as being synthesized de novo during the experimental run. Acetate isotopes used were $1-\left[{ }^{13} \mathrm{C}\right]$ or $2-\left[{ }^{13} \mathrm{C}\right]$ or $1,2-\left[{ }^{13} \mathrm{C}_{2}\right]$ acetic acid with $99 \%{ }^{13} \mathrm{C}$ enrichment purity (Sigma-Aldrich, St. Louis, MO). Peel plugs (11.5-mm diameter) were removed randomly from the surface of fruit and trimmed to 1- to 2-mm thickness. The resulting apple discs were placed skin-side-up onto the wetted filter paper discs and $\approx 40 \mu \mathrm{L}$ of additional incubation solution was added to each of the five discs on the slide. The slide was then placed into a horizontally oriented $30-\mathrm{mL}$ glass vial sealed with a cap housing a valved septum (Mininert valve 20/400 mm; Sigma-Aldrich). The samples were incubated for 5 or $21 \mathrm{~h}$ at $22^{\circ} \mathrm{C}$ (Sugimoto et al., 2021).
The incorporation of ${ }^{13} \mathrm{C}$ into headspace volatiles was analyzed by GC/MS as described (Sugimoto et al., 2021).

The production of acetate esters by tissue disks incubated in a buffered solution containing $\mathrm{MeOH}(20 \mathrm{~mm})$ and unlabeled acetate $(20 \mathrm{~mm})$ was measured using the GC/MS response for the fragment ion $m / z=43$. The effect of acetate and $\mathrm{MeOH}$ in the incubation medium on the production of acetate esters (ethyl acetate, propyl acetate, 2-methylpropyl acetate, butyl acetate, 2-methylbutyl acetate, and hexyl acetate) was determined statistically using analysis of variance at $P<0.05$; this was done separately for methyl acetate and nonmethyl acetates because methyl acetate incorporated the added methanol, but the other esters did not. Three biological replicates were used with two of those replicates being derived from a single fruit.

The generation of isotopologs (mass isotopomers) of headspace volatiles following feeding by $1-\left[{ }^{13} \mathrm{C}\right]-$ or $2-\left[{ }^{13} \mathrm{C}\right]$ or $1,2-\left[{ }^{13} \mathrm{C}_{2}\right]$ acetic acid were quantified as previously described (Sugimoto et al., 2021). The selected fragment ions $(\mathrm{m} / \mathrm{z})$, their formula, and the portion of the target molecule contributing the base fragment ion are provided (Supplemental Table 2). Fragment ions were chosen based on signal strength, lack of interference by other mass fragments, and inclusion of target portions of the analyte.

Isotope enrichment was assessed by integrating peaks corresponding to the heavier isotopologs, and mole percent enrichments were calculated by correcting for natural isotope content by unlabeled acetate control on the mass distribution as described by Biemann (1962). The mass isotopolog distribution is represented as the unlabeled mass fraction (M) of the selected fragment ion, the one ${ }^{13} \mathrm{C}$-labeled mass fraction $(\mathrm{M}+1)$, the two ${ }^{13} \mathrm{C}$-labeled mass fractions $(\mathrm{M}+2)$, and so on, up to the eight ${ }^{13} \mathrm{C}$-labeled mass fractions $(\mathrm{M}+8)$. Abundances of the base fragment ion and its heavier isotopologs were used to distinguish the extent of ${ }^{13} \mathrm{C}$ incorporation from $1-\left[{ }^{13} \mathrm{C}\right]-$ or $2-\left[{ }^{13} \mathrm{C}\right]$ or $1,2-$ $\left[{ }^{13} \mathrm{C}_{2}\right]$ acetic acid.

\section{Results}

Internal ethylene levels remained low until day 25 of the study, varying between 1.7 and $4.5 \mathrm{nmol} \cdot \mathrm{L}^{-1}\left[0.04\right.$ and $0.11 \mu \mathrm{L} \cdot \mathrm{L}^{-1}$, respectively (Fig. 1)]. On day 25 , the IEC rose to $21 \mathrm{nmol} \cdot \mathrm{L}^{-1}(0.5$ $\left.\mu \mathrm{L} \cdot \mathrm{L}^{-1}\right)$ and rapidly increased thereafter, reaching a peak of $12,400 \mathrm{nmol} \cdot \mathrm{L}^{-1}\left(300 \mu \mathrm{L} \cdot \mathrm{L}^{-1}\right)$ on day 47 . The IEC declined steadily thereafter, dropping to $1900 \mathrm{nmol} \cdot \mathrm{L}^{-1}\left(47 \mu \mathrm{L} \cdot \mathrm{L}^{-1}\right)$ on the final day of the study (day 71). The preclimacteric rate of respiratory $\mathrm{CO}_{2}$ production ranged from 250 to $350 \mu \mathrm{mol} \cdot \mathrm{kg}^{-1} \cdot \mathrm{h}^{-1}$ and increased simultaneously with the increase in the IEC on day 25. The respiratory climacteric persisted for $\approx 25 \mathrm{~d}$, reaching a maximum of $\approx 550 \mu \mathrm{mol} \cdot \mathrm{kg}^{-1} \cdot \mathrm{h}^{-1}$. The postclimacteric rate of $\mathrm{CO}_{2}$ production declined slowly, reaching a rate similar to that for preclimacteric fruit by the end of the study. Total amount of $\mathrm{CO}_{2}$ produced, integrated over the course of the experiment, was 791 $\mathrm{mmol} \cdot \mathrm{kg}^{-1}\left(34.8 \mathrm{~g} \cdot \mathrm{kg}^{-1}\right)$.

The initiation of ester biosynthesis paralleled the climacteric rise in fruit respiration and ethylene content (Fig. 1). Total ester production increased rapidly as the internal ethylene surpassed $21 \mathrm{nmol} \cdot \mathrm{L}^{-1}$. The respiratory climacteric peak and maximum rate of ester biosynthesis occurred on nearly the same date as the peak in the IEC (day 47). The maximum $\mathrm{CO}_{2}$ production was recorded on day 44 and the maximum ester production was recorded on day 49. As the internal ethylene level declined, total 
ester production decreased to a relatively steady level. The rate of ester production at its peak was less than 1/100th that of respiratory $\mathrm{CO}_{2}$ production on a molar basis.

ESTERS CLASSIFIED BY ALKANOATE (ACID-DERIVED) GROUP. Acetate esters predominated before, during, and after ripening in 'Redchief Delicious' apples, accounting for roughly 50\% to $80 \%$ of all esters (Fig. 2A and B). 2-Methylpropanoates were not detected in this study. Proportionally, in decreasing order, acetate, hexanoate, butanoate, and 2-methylbutanoate esters predominated before the onset of the ethylene rise (Fig. 2B). After the initiation of ripening, 2-methylbutanoate esters were the second most abundant esters and during the later, senescent stages, propanoate esters were the second most abundant alkanoate class.

Total acetate ester production increased steadily after the onset of autocatalytic ethylene production, reaching a high of $\approx 3.5 \mu \mathrm{mol} \cdot \mathrm{kg}^{-1} \cdot \mathrm{h}^{-1}$ by the end of the study (Fig. 3). Acetic acid emissions did not track acetate ester formation, but rather were steady from $20 \mathrm{~d}$ before the onset of ripening through the initial stages of ripening, declined in a short trough as total esters peaked, and increased thereafter (Fig. 3B). Acetate esters containing longer-chain alkyl moieties (e.g., hexyl, pentyl, butyl, and 2-methylbutyl) were present at very low levels before the onset of the ethylene production (Fig. 3C). At the initiation of ripening, 2-methylbutyl acetate production predominated. As ripening progressed, there was a greater production of shortchain acetate esters (e.g., propyl acetate and ethyl acetate). During senescence, ethyl acetate production predominated, increasing to a level $\approx 300$ times higher than at the beginning of ripening. When expressed proportionally, 2-methylbutyl and butyl acetate maintained high proportions until day 47, declining thereafter as ethyl and propyl acetates predominated (Fig. 3D). Hexyl acetate was proportionally consistent during ripening, ranging between $5 \%$ and $15 \%$ of the total.

Propanoate ester production was relatively low during the early stages of ripening, but increased rapidly thereafter, peaking on day 47 (Fig. 4A). The late increase in propanoate esters was reflected by a similar late increase in propanoate emissions (Fig. 4B). The most abundant propanoate esters were formed from ethanol and 1-propanol (Fig. 4C). Proportionally, butyl propanoate predominated during the preclimacteric stages and ethyl propanoate dominated after the respiratory peak (Fig. 4D).

Butanoate ester production increased steadily to a peak on day 49, then declined (Fig. 5A). Butanoic acid emanation climbed to an initial peak, declined as its derivative esters peaked, and then recovered, reaching a second peak thereafter (Fig. 5B). As butanoate esters peaked, ethyl and propyl butanote were produced in the greatest amounts (Fig. 5C). Proportionally, hexyl and butyl butanoate predominated early in ripening with ethyl and propyl butanoate predominating later in senescence; 2-methylbutyl butanoate never exceeded 5\% of the total at any time (Fig. 5D).

2-Methylbutanoate ester production was characterized as having an extended period of maximum production with a peak on day 47 and a shoulder on day 33 (Fig. 6A). The initial shoulder of the maxima was largely due to a spike in hexyl 2-methylbutanoate and the latter portion of the maxima was due to high levels of hexyl, propyl, butyl, and ethyl hexanoates (Fig. 6C). Proportionally, 2-methylbutanoate esters formed abundantly with 1-hexanol at onset of ripening, but ethanol and 1-propanol predominated at the ester peak and through senescence (Fig. 6D).

Hexanoate esters exhibited a pattern of a peak on day 47 with a shoulder on day 33 (Fig. 7A), with butyl and hexyl hexanoates being produced at the greatest rates at the time of the shoulder and ethyl, propyl, and butyl hexanoates predominating at the peak of production (Fig. 7C). A spike in hexanoic acid was detected at the second peak in hexanoates, declining thereafter (Fig. 7B). The hexanoates from the pentanol and the branched-chain alcohols (2methyl-1-propanol and 2-methyl-1-butanol) were present in very low quantities throughout. Proportionally, hexanoates formed with 1-hexanol dominated the unripe stage. Afterward, there were peaks in butyl hexanoate early in ripening, propyl hexanoate at the climacteric peak, and ethyl hexanoate at the end of the study (Fig. 7D).

Pentanoate and heptanoate esters, present in low amounts, had very similar patterns (Figs. 8 and 9). These most closely paralleled that of butanoate esters. Octanoate esters were also produced in low amounts (Fig. 10). Pentanoic, heptanoic, and octanoic acids were not detected. The patterns for butyl, propyl, and ethyl esters were consistent for these three ester classes, with butyl esters tending to predominate early followed by a rise in propyl esters, and finally, ethyl esters being most abundant during the latter stages of senescence.

Correlations between the production of an ester and its respective alkanoate group (ester precursor of acid) were generally poor (Fig. 11). The coefficient of determination for acetic, propanoic, butanoic, 2-methylbutanoic, and hexanoic acids and the esters containing their respective alkanoate group were, respectively, $0.07,0.57,0.18,0.45$, and 0.17 . All slopes of the fitted line were significantly different from $0(P<0.05)$.

Esters ClASSIFIED BY ALKYL (ALCOHOL-DERIVED) GROUP. Unlike when classified by alkanoate moieties, no one class of esters predominated in 'Redchief Delicious' apple according to its alkyl moiety (Fig. 12A and B). As noted previously for many of

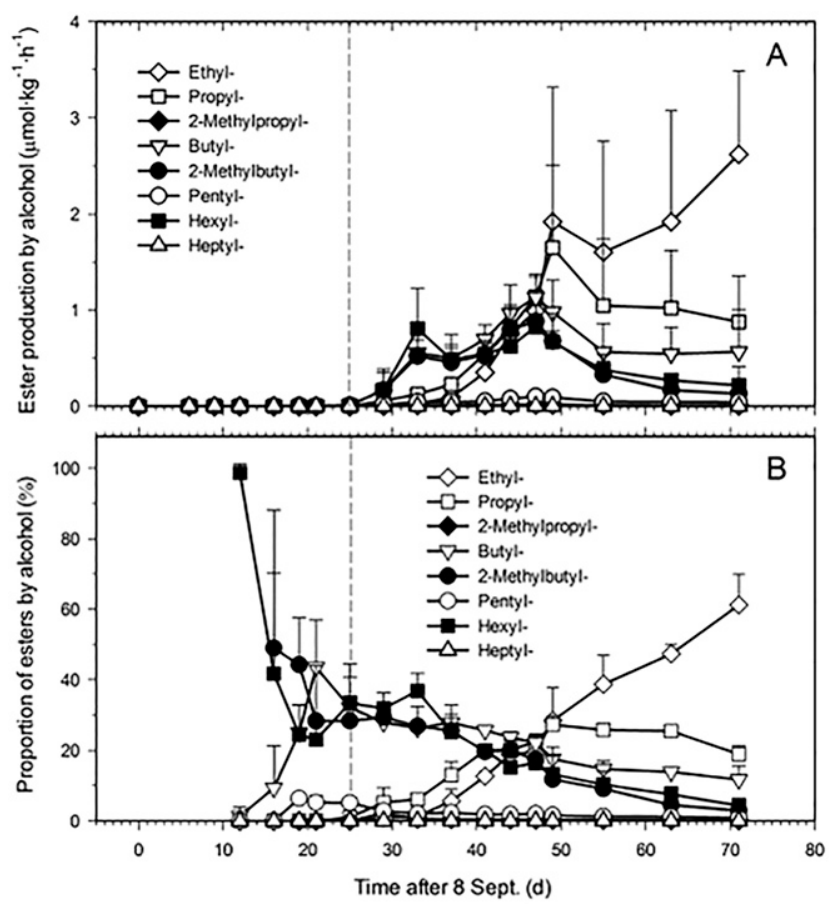

Fig. 12. Pattern of esters classed by the alkyl (alcohol) moiety during ripening and senescence of 'Redchief Delicious' apple. The volatile profile was tracked for fruit held at $20^{\circ} \mathrm{C}$ from 3 weeks before 8 weeks after the onset of the ethylene climacteric (indicated by dashed vertical line). (A) Ester production. (B) Ester proportions (\% of total alcohol esters). Each symbol represents the average of five replications \pm SD. 
the esters individually, as ripening progressed, the chain-length of the alcohol-derived portion of the predominant ester typically declined. Early in ripening, there was predominance in hexyl, butyl, and 2-methylbutyl esters. This was followed by a sharp rise in the production of propyl and ethyl esters, which peaked after the ethylene maximum on day 49. During the later stages of ripening, ethyl esters predominated, comprising more than $60 \%$ of all esters by the conclusion of the study. Octyl esters were not detected.

All alkyl moieties tended to be formed predominately with acetate throughout the period of evaluation (Figs. 13-20). The exception was for hexyl esters, for which hexyl 2-methylbutanoate predominated during the early stages of ripening (Fig. 19C). Ethyl and propyl esters rose to a peak on day 49 , remaining elevated thereafter (Figs. 13 and 14). The production pattern for all other esters differed, most having a shoulder (2-methylpropyl, butyl, pentyl, and heptyl esters) or elevated shoulder (hexyl esters, primarily due to the elevated shoulder patterns for hexyl acetate and hexyl 2-methylbutanoate) during the early stages of ripening (on or near day 33), followed by a second peak on day 47 or 49 (Figs. 15-20) when classed by their alkyl moiety. Butyl esters tended to be formed with hexanoates before initiation of the autocatalytic ethylene production until climacteric peak and tended to form with propanoates thereafter (Fig. 16C and D). 2-Methylbutyl, pentyl, and heptyl esters were almost exclusively acetate esters (Figs. 17, 18, and 20). In contrast, hexyl esters were formed with a broad mix of acids (Fig. 19).

Ethanol, 1-propanol, and 1-hexanol emissions behaved similarly, increasing steadily as ripening and senescence progressed (Figs. 13B, 14B, and 19B, respectively). However, rates of production differed dramatically; 1-propanol emission was approximately one-tenth that of ethanol and 1-hexanol was approximately onetenth that of 1-propanol. Emission of 1-butanol and 2-methyl-1butanol peaked simultaneously with the peak in the ethylene, declining thereafter (Figs. 16B and 17B, respectively). 1-Pentanol, 2-methyl-1-propanol, and 1-heptanol were not detected.

Correlations between the production of an alcohol precursor and the production of esters containing its respective alkyl group were generally much higher than the correlations between acids and their respective esters, with the exception of 1-hexanol (Fig. 11). The coefficient of determination for ethanol, 1-propanol, 1-butanol, 2-methyl-1-butanol, and 1-hexanol and the esters containing their respective alkyl group were, respectively, $0.72,0.60$, $0.89,0.83$, and 0.35 . All slopes of the fitted line were significantly different from $0(P<0.05)$.

Total ester production throughout the study period was summed and is displayed in a matrix based on the acid (alkanoate) and alcohol (alkyl) moieties in the ester (Table 2). Over the course of ripening, the nine most abundant esters produced, in decreasing order were ethyl acetate, butyl acetate, propyl acetate, 2-methylbutyl acetate, ethyl propanoate, hexyl acetate, ethyl butanoate, hexyl 2-methylbutanoate, and ethyl 2-methylbutanoate. Approximately half of the possible alcohol/acid combinations were not detected in this study. For those esters (e.g., hexyl, butyl, and 2-methylbutyl acetates; butyl and hexyl butanoates; and butyl and hexyl hexanoates) detected at very low levels before the onset of the climacteric, production increased many-fold (2177-, 304-, 2379-, 317-, $390-$, 608-, and 248-fold, respectively) as ripening progressed. Total ester production for the entire developmental period was $\approx 4.0 \mathrm{mmol} \cdot \mathrm{kg}^{-1}\left(0.5 \mathrm{~g} \cdot \mathrm{kg}^{-1}\right)$, of which, $\approx 56 \%$ on a molar basis were acetate esters. Total $\mathrm{CO}_{2}$ production per kilogram fruit was 197-fold higher than ester production on a molar basis and 70-fold higher than ester production on a mass basis.

The predicted impact of esters and alcohols on human perception of fruity/floral (F), overripe/cheesy/fatty/off-flavor (O), grassy/green (G), alcoholic/winey (A), or sweet/ether/solvent/ chemical (S) categories of aroma notes was highly dependent on the developmental stage (Fig. 21). The predicted aroma impact of category $\mathrm{F}$ notes increased most rapidly after the onset of ripening on day 25 , accompanied by a lower level of category $\mathrm{S}$ aroma notes. After day 40, there was a rapid rise in the predicted aroma impact of category $\mathrm{O}, \mathrm{G}$, and A notes that peaked on day 49 and declined slightly or persisted thereafter at elevated levels.

INCORPORATION OF LABEL FROM ${ }^{13}$ C-LABELED AND UNLABELED ACETATE INTO ESTERS. Addition of $\mathrm{MeOH}$ in the incubation solution for skin tissue discs enhanced the production of methyl acetate; however, acetate inclusion did not affect methyl acetate production (Tables 3 and 4). For esters not possessing a methyl group, neither $\mathrm{MeOH}$ nor acetate feeding affected ester production (Table 4).

Incubation with ${ }^{13} \mathrm{C}$-acetate isotopologs demonstrated that the applied acetate was incorporated into esters (Figs. 22 and 23). Enrichment of 1-propanol, 2-methyl-1-butanol, methyl propanoate, and methyl 2-methylbutanoate from labeled acetate were similar, with label being consistent with the incorporation of the C-2 atom of a single acetate into the alcohols or into the alkanoate portion of the methyl ester (Fig. 22). Enrichment was $\approx 15 \%$ to $20 \%$ for 1-propanol and 2-methyl-1-butanol and $15 \%$ to $25 \%$ for methyl propanoate and methyl 2-methylbutanoate. The extent of labeling was lower, but evident for 1-butanol and the alkanoate moieties of the other three methyl esters evaluated (Fig. 23). Enrichment of the $\mathrm{M}+1$ isotopolog of 1-butanol, methyl butanoate, and methyl pentanoate was derived from $1-\left[{ }^{13} \mathrm{C}\right]-$ or $2-$ $\left[{ }^{13} \mathrm{C}\right]$ or $1,2-\left[{ }^{13} \mathrm{C}_{2}\right]$ acetic acid. The $\mathrm{M}+1$ isotopolog of methyl hexanoate, on the other hand, gained most of its label from 1$\left[{ }^{13} \mathrm{C}\right]-$ or $2-\left[{ }^{13} \mathrm{C}\right]$ acetate and its $\mathrm{M}+2$ isotopolog received most of its label from $1,2-\left[{ }^{13} \mathrm{C}_{2}\right]$ acetic acid. $\mathrm{M}+4$ isotopologs of 1butanol, methyl butanoate, and methyl hexanoate were primarily labeled by $1,2-\left[{ }^{13} \mathrm{C}_{2}\right]$ acetic acid.

Label incorporation into the alkanoate portion of butyl esters was similar to that for the alkanoate portion of methyl esters (Fig. 23). Enrichment of the $M+1$ isotopolog of butyl propanoate and butyl 2-methylbutanoate was primarily via the $\mathrm{C}-2$ position, based on labeling by $2-\left[{ }^{13} \mathrm{C}\right]$ and $1,2-\left[{ }^{13} \mathrm{C}_{2}\right]$ acetate and not $1-\left[{ }^{13} \mathrm{C}\right]$ acetate. The labeling of the alkanoate portion of butyl butanoate was similar to labeling of that for methyl butanoate, with the $\mathrm{M}+1$ isotopolog receiving label from all three isotopes of acetate. In addition, enrichment of the $\mathrm{M}+4$ isopotolog by $1,2-\left[{ }^{13} \mathrm{C}_{2}\right]$ was clearer than for methyl butanoate, indicating the incorporation of two acetate molecules. The labeling of butyl hexanoate was very similar to, but lower than, that of methyl hexanoate. However, because the full alkanoate moiety could be assessed for butyl hexanoate, label of the $M+6$ could also be evaluated. Label of $\mathrm{M}+6$ was detected from $1,2-\left[{ }^{13} \mathrm{C}_{2}\right]$ acetate, indicating the incorporation of three acetate molecules. Although labeling was low, butyl octanoate evidenced the incorporation up to four acetate molecules.

\section{Discussion}

The patterns for the production of esters and their precursor alcohols and acids have not been previously described at the level 

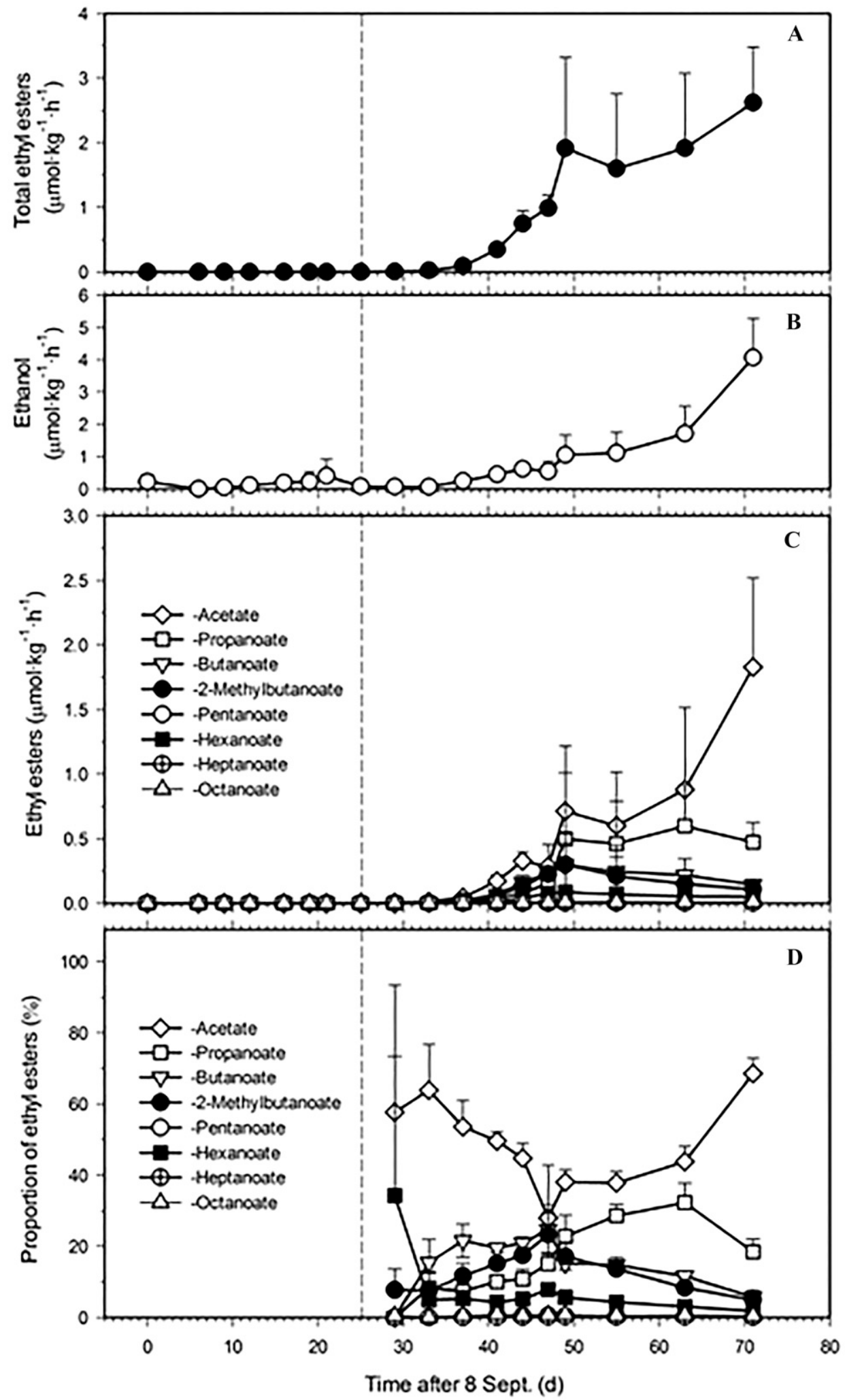

Fig. 13. Pattern of ethyl esters during ripening and senescence of 'Redchief Delicious' apple. The volatile profile was tracked for fruit held at $20^{\circ} \mathrm{C}$ from 3 weeks before 8 weeks after the onset of the ethylene climacteric (indicated by dashed vertical line). (A) Total ethyl ester production. (B) Ethanol production. (C) Ethyl ester production classified by acid portions. (D) Ester proportions (\% of total ethyl esters). Each symbol represents the average of five replications \pm SD.

of detail offered in this study. Nevertheless, the composition of esters was qualitatively similar to that found by other investigators (Brackmann et al., 1993; Mattheis et al., 1991; Rowan et al.,
1996; Song and Bangerth, 1996; Vanoli et al., 1995). In particular, the high concentrations of 2-methylbutyl acetate, hexyl acetate, and butyl acetate during the early climacteric are similar to 

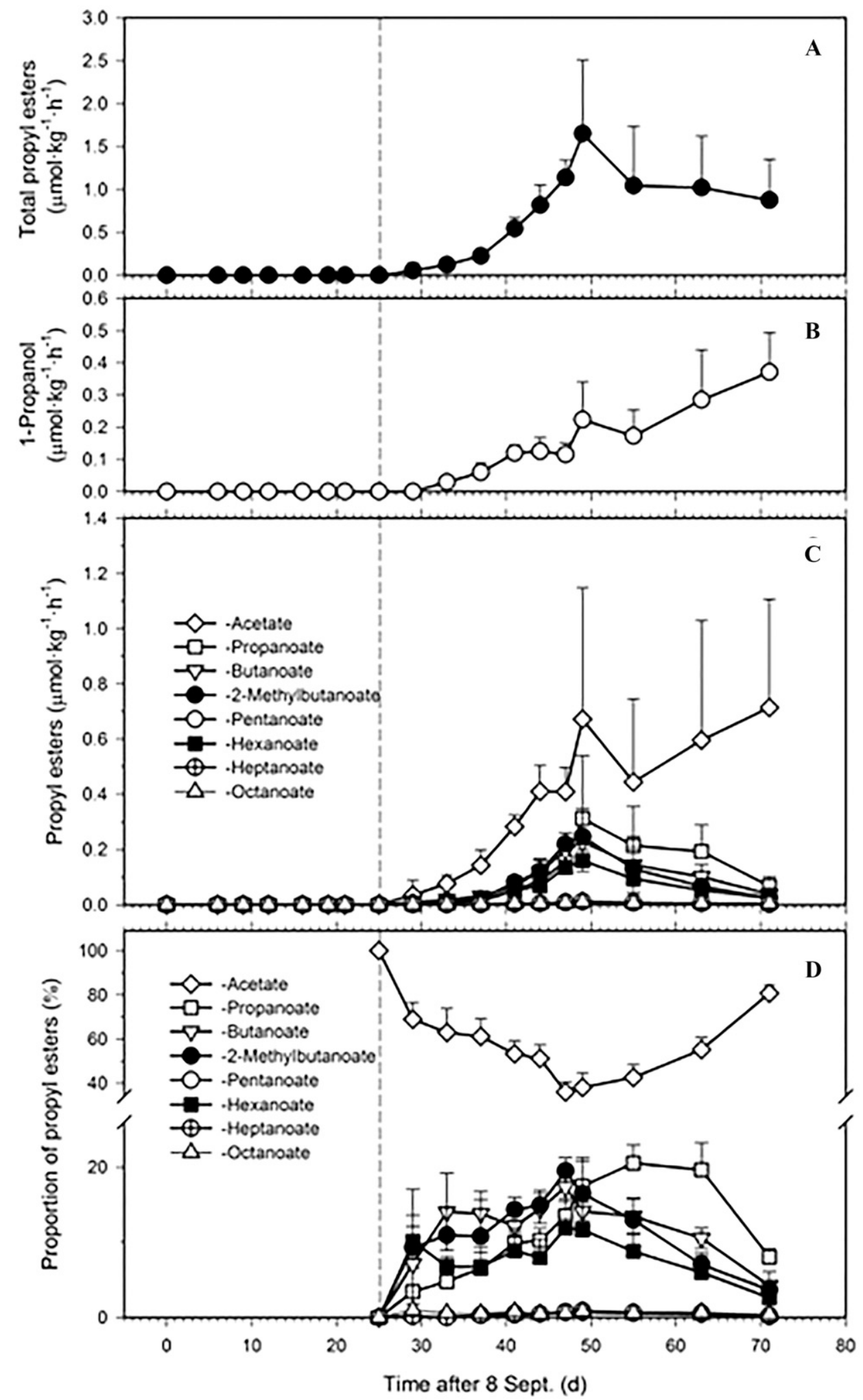

Fig. 14. Pattern of propyl esters during ripening and senescence of 'Redchief Delicious' apple. The volatile profile was tracked for fruit held at $20^{\circ} \mathrm{C}$ from 3 weeks before 8 weeks after the onset of the ethylene climacteric (indicated by dashed vertical line). (A) Total propyl ester production. (B) 1-Propanol production. (C) Propyl ester production classified by acid portions. (D) Ester proportions (\% of total propyl esters). Each symbol represents the average of five replications $\pm \mathrm{SD}$.

those previously reported for other 'Delicious' strains (Berger and Drawert, 1984; Brackmann et al., 1993; Dimick and Hoskin, 1983; Fellman et al., 1993, 2000; Kakiguchi et al., 1986; Mattheis et al., 1991, 1995). These three compounds are considered primary aroma impact compounds in apple (Dimick and Hoskin, 1983; Fellman et al., 2000). The high proportion of acetate esters 


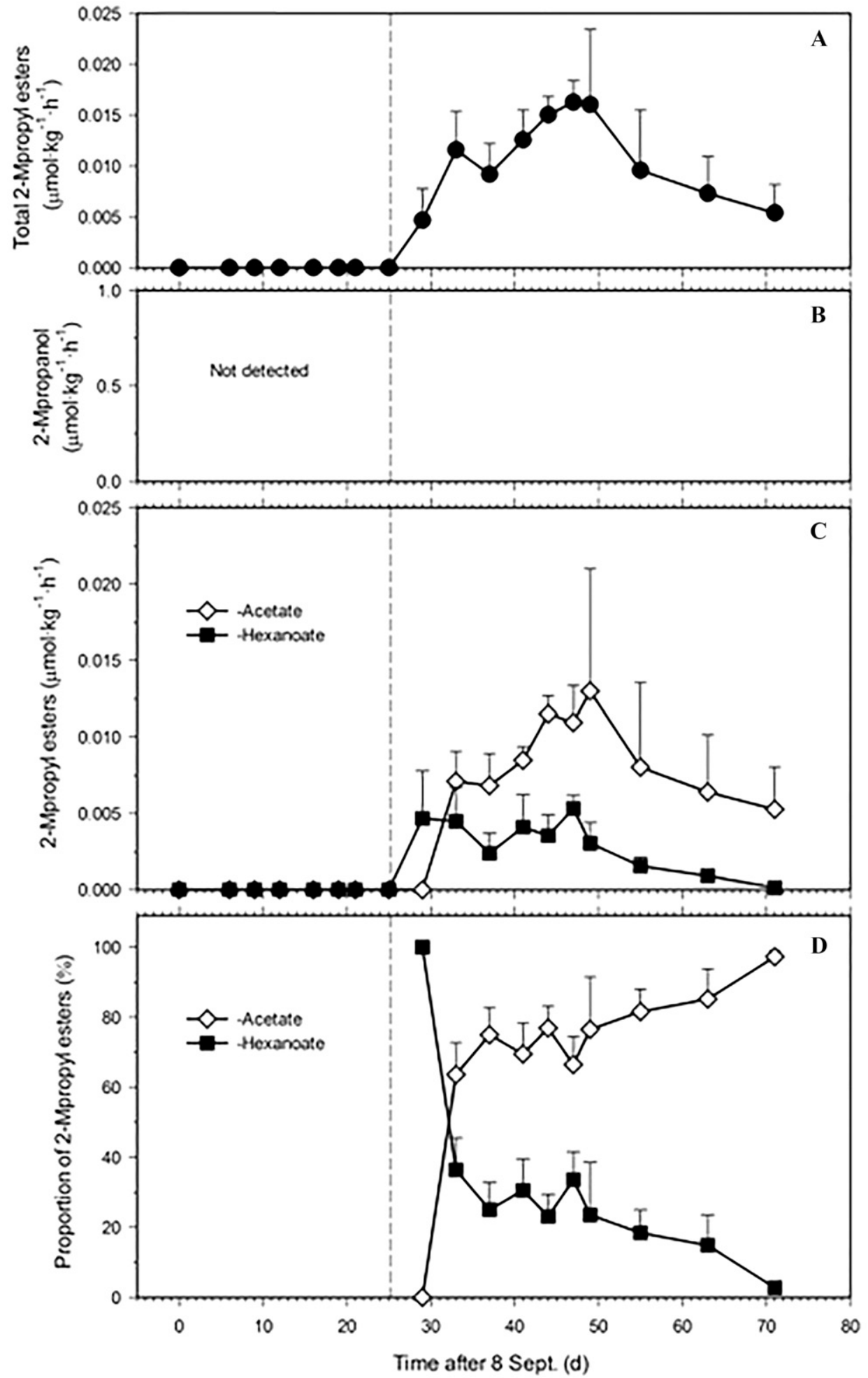

Fig. 15. Pattern of 2-methylpropyl (2-Mpropyl) esters during ripening and senescence of 'Redchief Delicious' apple. The volatile profile was tracked for fruit held at $20^{\circ} \mathrm{C}$ from 3 weeks before 8 weeks after the onset of the ethylene climacteric (indicated by dashed vertical line). (A) Total 2-Mpropyl ester production. (B) 2-Methyl-1-propanol (2-Mpropanol) production. (C) Ester production. (D) Ester proportions (\% of total 2-Mpropyl esters). Each symbol represents the average of five replications \pm SD.

$(\approx 56 \%$ of all the esters quantified were acetate esters $)$ in 'Delicious' strains might be due to abundant acetyl-CoA in the fruit tissue (Nursten, 1970). This supposition is supported by the lack of a boost in acetate ester production by 'Redchief
Delicious' tissue disks when incubated with acetic acid in this study.

The marked increase in all classes of esters following the onset of autocatalytic ethylene production depends on the action of 

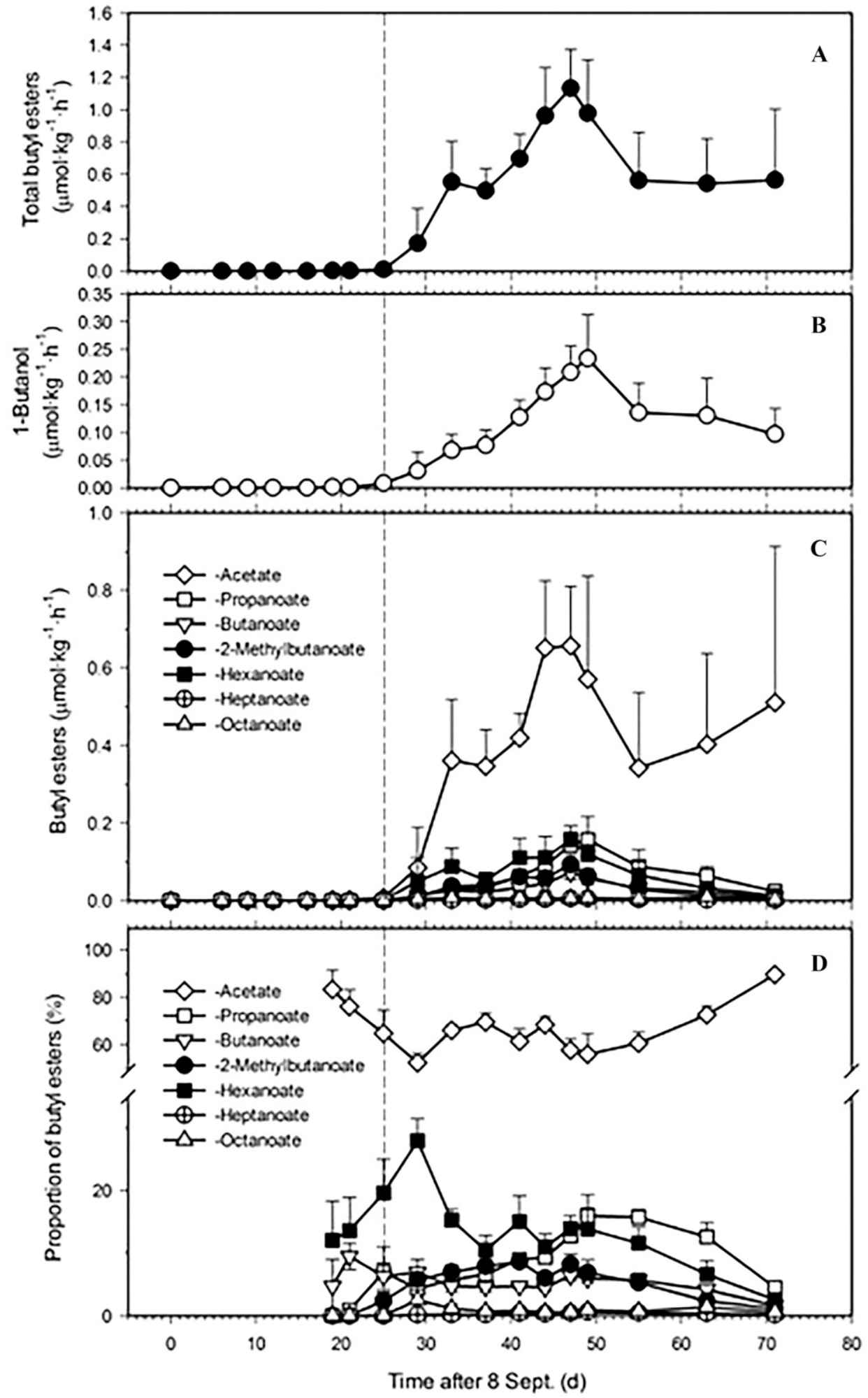

Fig. 16. Pattern of butyl esters during ripening and senescence of 'Redchief Delicious' apple. The volatile profile was tracked for fruit held at $20{ }^{\circ} \mathrm{C}$ from 3 weeks before 8 weeks after the onset of the ethylene climacteric (indicated by dashed vertical line). (A) Total butyl ester production. (B) 1-Butanol production. (C) Butyl ester production classified by acid portions. (D) Ester proportions ( $\%$ of total butyl esters). Each symbol represents the average of five replications \pm SD.

ethylene in apple (Defilippi et al., 2005; Fan et al., 1998; Ferenczi et al., 2006; Song and Bangerth, 1996). The maximum ester production occurring near the peaks in ethylene content and respiratory activity is also consistent with the other authors (Brown et al., 1966; Dirinck et al., 1989; Mattheis et al., 1991; Tressl and Drawert, 1973). Although ethylene action enhances the expression of some $A A T$ genes in apple (Defilippi et al., 2005; Li et al., 2006; Zhu et al., 2008), it also drives an alteration in metabolism 

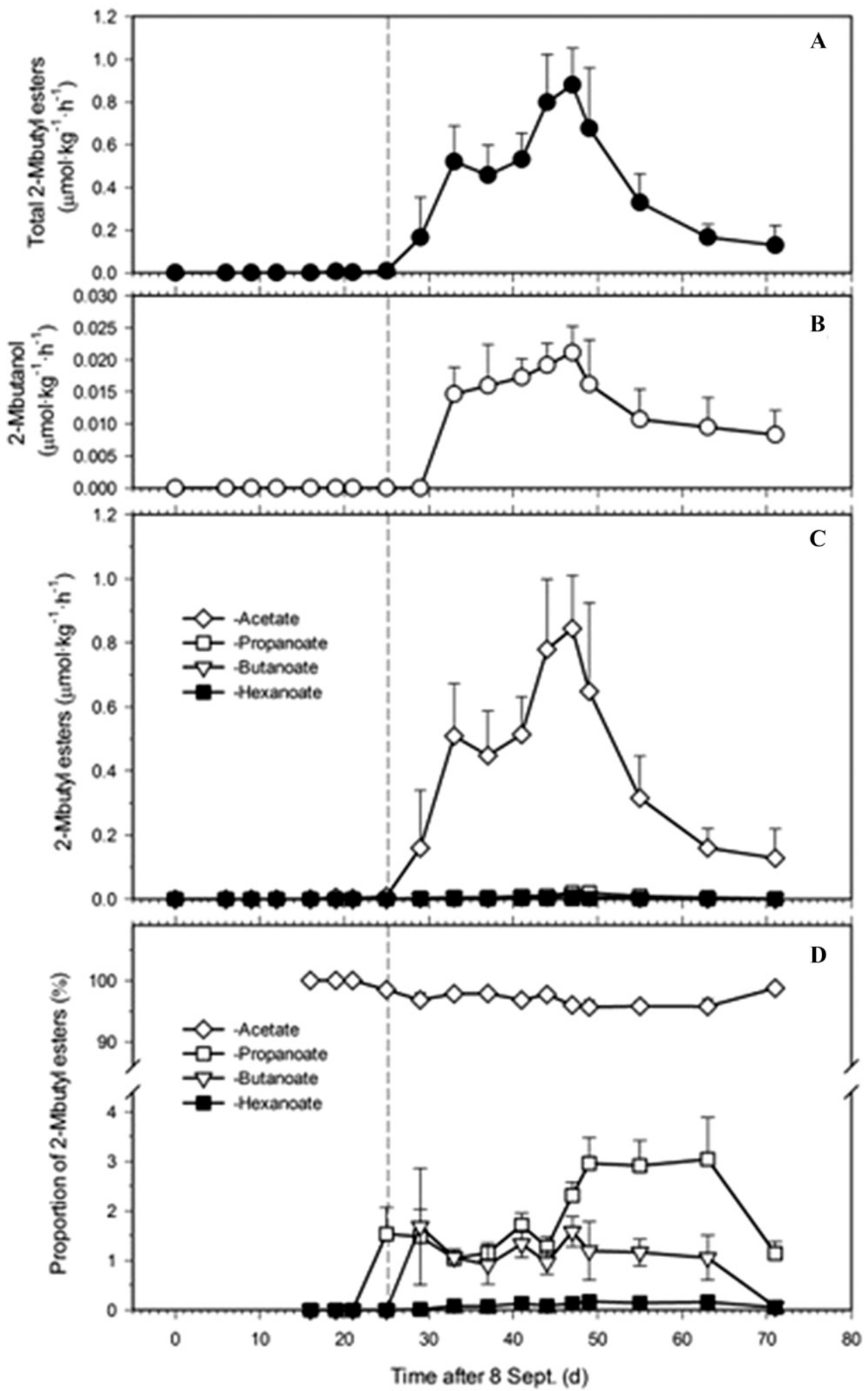

Fig. 17. Pattern of 2-methylbutyl (2Mbutyl) esters during ripening and senescence of 'Redchief Delicious' apple. The volatile profile was tracked for fruit held at $20^{\circ} \mathrm{C}$ from 3 weeks before 8 weeks after the onset of the ethylene climacteric (indicated by dashed vertical line). (A) Total 2-methylbutyl ester production. (B) 2-methyl-1-butanol (2-Mbutanol) production. (C) 2-Mbutyl ester production classified by acid portions. (D) Ester proportions (\% of total 2-Mbutyl esters). Each symbol represents the average of five replications \pm SD.

that is signified by the climacteric respiratory rise. Thus, ethylene promotes numerous physiological processes, many of which may contribute to the synthesis of substrates used in the formation of esters (Contreras et al., 2015; Sugimoto et al., 2021). Bangerth et al. (1998) further argue that the increase in fruit respiration also provides the necessary 

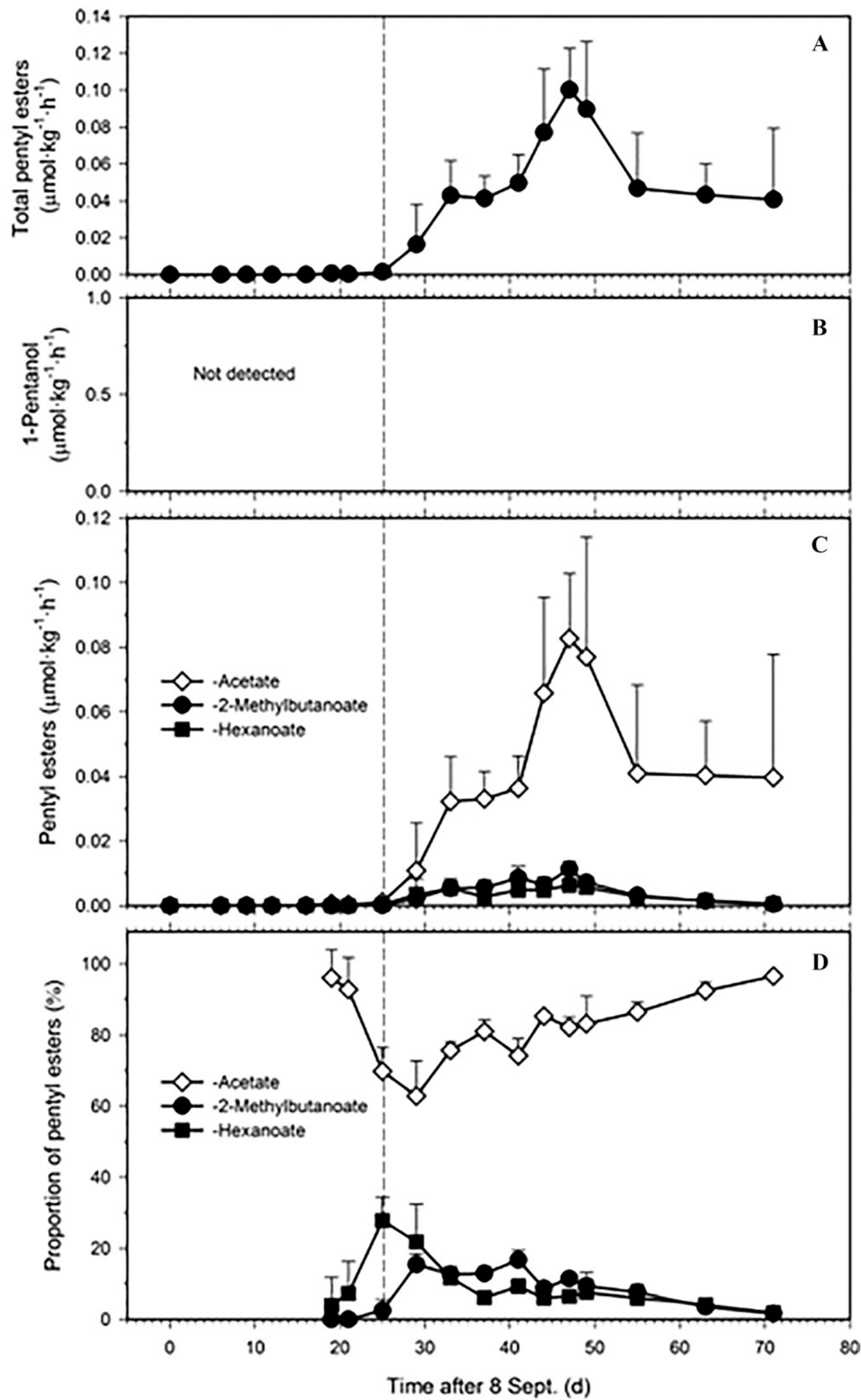

Fig. 18. Pattern of pentyl esters during ripening and senescence of 'Redchief Delicious' apple. The volatile profile was tracked for fruit held at $20^{\circ} \mathrm{C}$ from 3 weeks before 8 weeks after the onset of the ethylene climacteric (indicated by dashed vertical line). (A) Total pentyl ester production. (B) 1-Pentanol production. (C) Pentyl ester production classified by acid portions. (D) Ester proportions (\% of total pentyl esters). Each symbol represents the average of five replications \pm SD.

energy (e.g., ATP, NADPH) for the synthesis of aroma volatile precursors.

In the current study, the detection of several esters at low levels before onset of ethylene production suggests that the capacity to make esters exists well before the onset of ripening. Mattheis et al. (1991) and Willaert et al. (1983) found similar early production of esters by intact 'Bisbee Delicious' and 'Golden Delicious' fruit, respectively. Expression studies for some MdAAT/MpAAT genes 


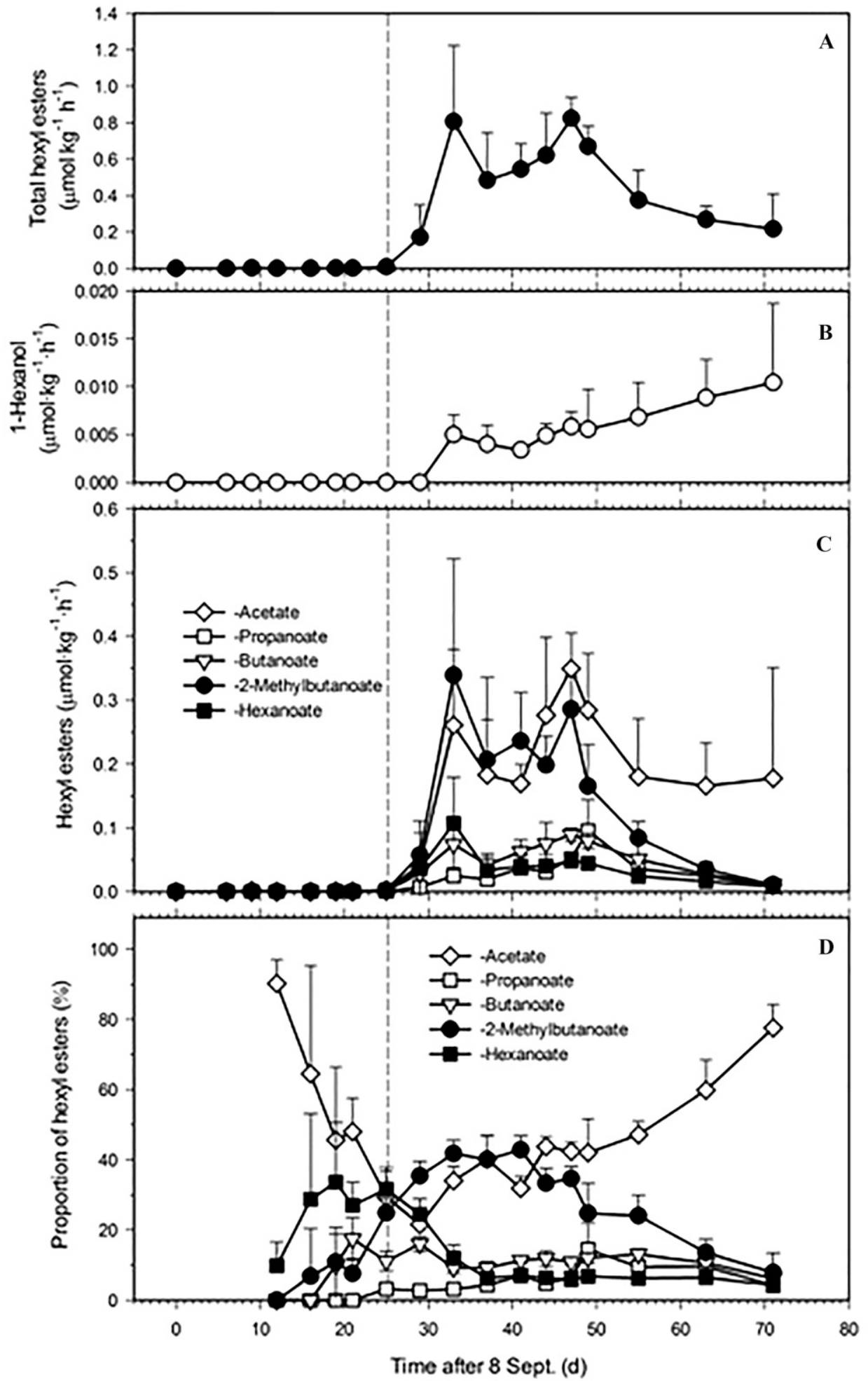

Fig. 19. Pattern of hexyl esters during ripening and senescence of 'Redchief Delicious' apple. The volatile profile was tracked for fruit held at $20^{\circ} \mathrm{C}$ from 3 weeks before 8 weeks after the onset of the ethylene climacteric (indicated by dashed vertical line). (A) Total hexyl ester production. (B) 1-Hexanol production. (C) Hexyl ester production classified by acid portions. (D) Ester proportions (\% of total hexyl esters). Each symbol represents the average of five replications and as means \pm SD.

(Souleyre et al., 2005; Zhu et al., 2008) and tests for AAT activity from apple tissues (Li et al., 2006), indicate some level of AAT activity is present in apple fruit well in advance of ripening. Ferenczi et al. (2006) also found that AAT activity was, in part, independent of ripening after finding that application of exogenous alcohols and acids would induce the formation of esters in 'Redchief Delicious' apples whose ripening and native ester production were inhibited by 1-methylcyclopropene (1-MCP). In 

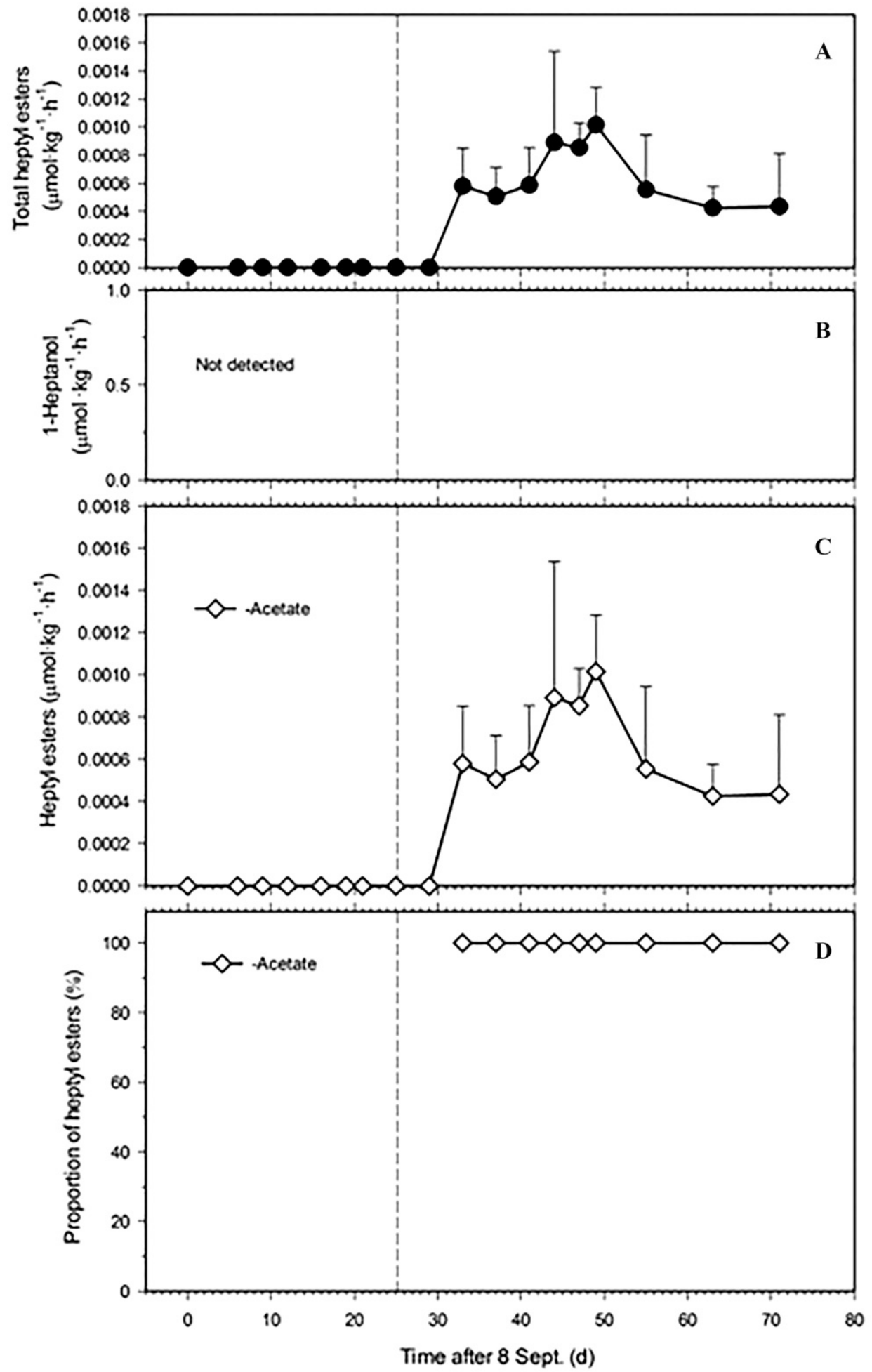

Fig. 20. Pattern of heptyl esters during ripening and senescence of 'Redchief Delicious' apple. The volatile profile was tracked for fruit held at $20{ }^{\circ} \mathrm{C}$ from 3 weeks before 8 weeks after the onset of the ethylene climacteric (indicated by dashed vertical line). (A) Total heptyl ester production. (B) 1-Heptanol production. (C) Heptyl ester production classified by acid portions. (D) Ester proportions (\% of total heptyl esters). Each symbol represents the average of five replications and as means \pm SD.

preclimacteric banana, Jayanty et al. (2002) fed fruit tissues with alcohols and acids before the onset of ripening-related ester production and found extensive incorporation into esters. Unlike apple, ester biosynthesis in banana trails the onset of ripening significantly, suggesting something more complex than a simple response to ethylene in that fruit, however.

The progressive shift from longer to shorter carbon chain alcohols as ripening progressed is consistent with Vanoli et al. (1995) 


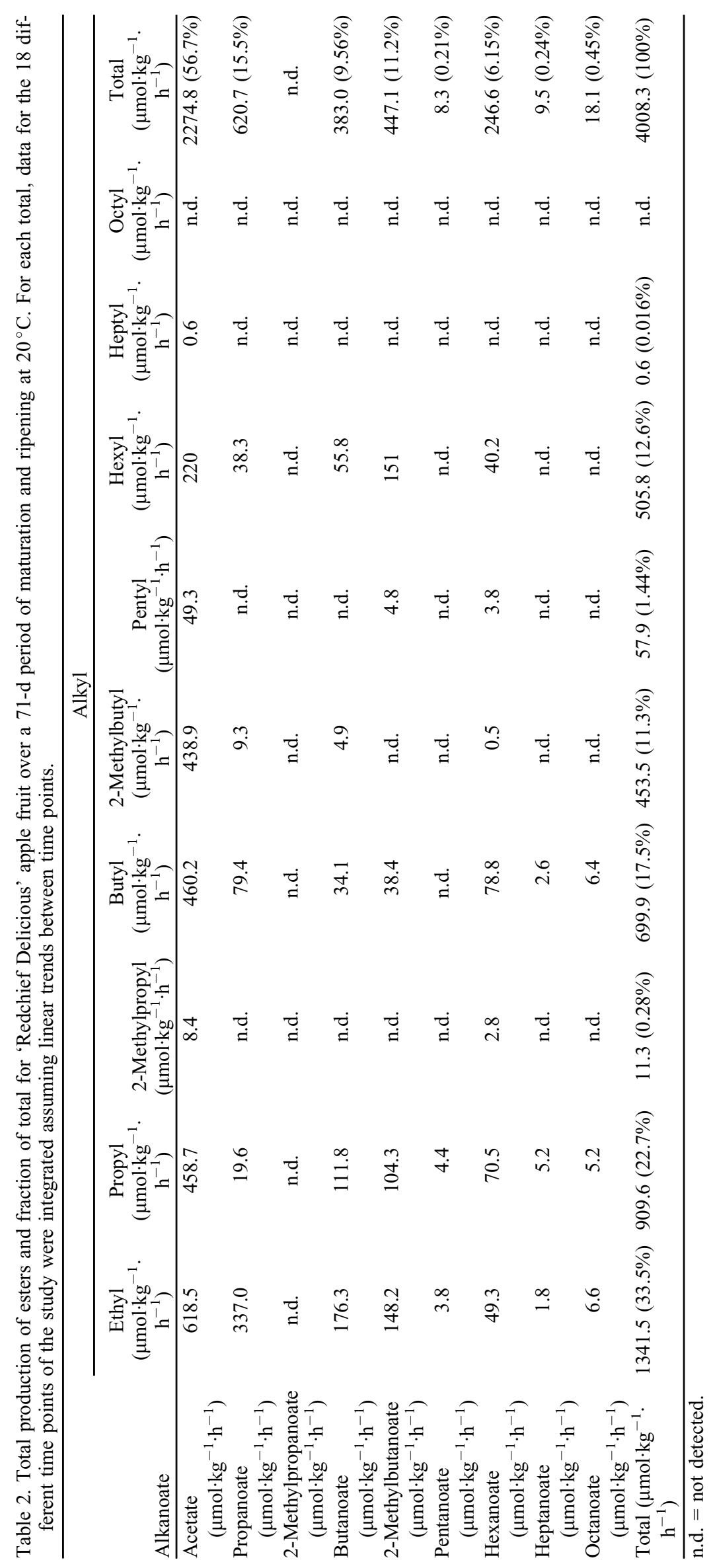


who found a high content of low boiling-point esters and alcohols later in ripening and by Willaert et al. (1983) who correlated overripeness with more ethyl esters. The rise in the proportion of propyl and ethyl esters appears to reflect changes in the availability of 1propanol and ethanol, the production of which increased steadily as ripening and senescence progressed. It is not clear why hexyl esters predominate before ripening, but it may be related to the high activity of AAT with 1-hexanol (Pérez et al., 1993; Souleyre

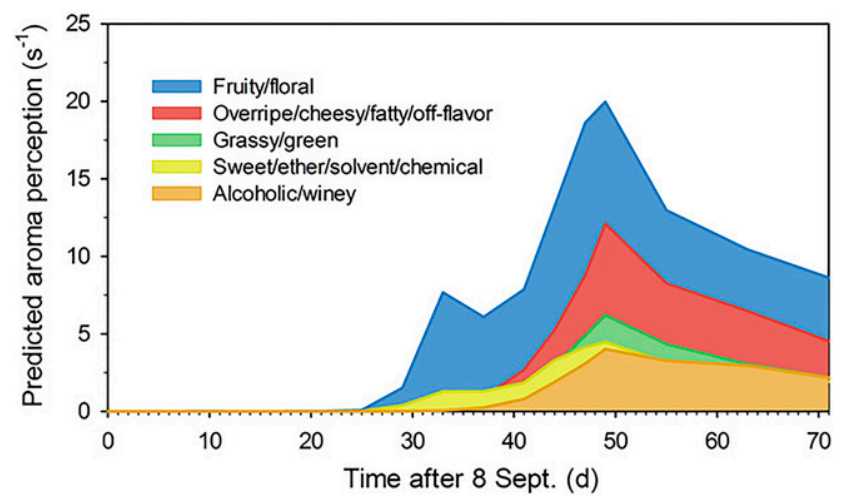

Fig. 21. Anticipated perceptions of aroma from ripening 'Redchief Delicious' apple fruit based on the combined impact of 26 volatile esters and alcohols. Perceptions are calculated based on production rates provided in Figs. 3-10 and Figs. 13-20, their corresponding odor thresholds, and their sensory descriptors as given in Table 1. et al., 2005). A pattern of increasing carbon-chain length was not as clear for the acid portion of the esters. This may, in part, be due to the copious quantities of acetate esters diluting the remaining esters. It also suggests different pathways for the creation of alcohols and acids or their interconversion predominate at different times during ripening (Williams and Knee, 1977).

The high correlation coefficients for all alcohols and some, but not all, acids and their respective esters supports previous suggestions that ester biosynthesis is dependent on the synthesis of precursors in specific instances (De Pooter et al., 1983; Ferenczi et al., 2006; Knee and Hatfield, 1981; Song and Bangerth, 1996). The lack of a strong relationship between acid content and ester production for acetate, butanoate, and hexanoate may reflect that, like acetate, the latter two substrates exist at or near saturating levels for AAT.

The impact of the various esters and alcohols on aroma perception cannot be precisely determined a priori based on volatile production rates and data for descriptors and odor thresholds (Chambers and Koppel, 2013). Human perception will depend on the biology of the perceiver, the nature of the response curve for each volatile, matrix effects, numerous factors in the environment, and the way in which the person interacts with the product during sensory assessment. However, despite the shortcomings of various approaches, it is important to develop some measure that will enable using quantitative measures to predict aroma perceptions without performing the sensory analyses.

Table 3. Acetate ester production for fruit tissue disks treated with buffered water $(\mathrm{pH} 7)$ or buffered acetic acid solution ( $\mathrm{pH} 7,20$ mm) with and without methanol $(\mathrm{MeOH}, 20 \mathrm{~mm})$. 2MP and 2MB acetate represent 2-methylpropyl and 2-methylbutyl acetate, respectively.

\begin{tabular}{lcccc}
\hline & \multicolumn{2}{c}{- Acetate } & & \multicolumn{2}{c}{+ Acetate } \\
\cline { 2 - 5 } Compound & $\begin{array}{c}-\mathrm{MeOH}(\mathrm{m} / z \text { 43, } \\
\text { in millions })\end{array}$ & $\begin{array}{c}\text { MeOH }(\mathrm{m} / z \text { 43, } \\
\text { in millions })\end{array}$ & $\begin{array}{c}-\mathrm{MeOH}(\mathrm{m} / z \text { 43, } \\
\text { in millions })\end{array}$ & $\begin{array}{c}\text { MeOH }(\mathrm{m} / z \text { 43, } \\
\text { in millions })\end{array}$ \\
\hline Methyl acetate & 3.21 & 15.57 & 2.98 & 12.44 \\
Ethyl acetate & 14.85 & 6.16 & 9.67 & 27.36 \\
Propyl acetate & 6.98 & 10.28 & 6.96 & 6.11 \\
2MP acetate & 8.16 & 8.56 & 33.62 & 35.16 \\
Butyl acetate & 34.86 & 36.46 & 36.57 & 47.23 \\
2MB acetate & 43.73 & 49.10 & 3.19 & 4.75 \\
Pentyl acetate & 2.94 & 4.56 & 15.13 & 17.84 \\
Hexyl acetate & 14.93 & 18.65 & & \\
\hline
\end{tabular}

Table 4. Analysis of variance for the impact of methanol (MeOH, $20 \mathrm{~mm})$ and acetate $(20 \mathrm{~mm})$ solutions on the production of methyl acetate or esters not possessing a methyl moiety by skin tissue disks of ripe 'Redchief Delicious' apple fruit incubated at $20^{\circ} \mathrm{C}$ for $21 \mathrm{~h}$. The log of the total ion count response of the mass spectrometer was used to normalize the data for statistical analysis.

\begin{tabular}{lcccc}
\hline Source of variation & df & Sum of squares & Mean square & $F$ \\
\hline \\
MeOH & 1 & Methyl acetate & & \\
Acetate & 1 & 1.133 & 1.133 & 11.507 \\
$\mathrm{MeOH} \times$ Acetate & 1 & 0.0124 & 0.0124 & 0.126 \\
Residual & 4 & 0.000607 & 0.000607 & 0.00617 \\
Total & 7 & 0.394 & 0.0985 & 0.027 \\
& & 1.54 & 0.22 & 0.941 \\
$\mathrm{MeOH}$ & 1 & 0.182 & 0.182 & 1.122 \\
Acetate & 1 & 0.0215 & 0.0215 & 0.132 \\
MeOH $\times$ Acetate & 1 & 0.0389 & 0.0389 & 0.239 \\
Residual & 52 & 8.443 & 0.162 & 0.718 \\
Total & 55 & 8.685 & 0.158 & 0.627 \\
\hline
\end{tabular}



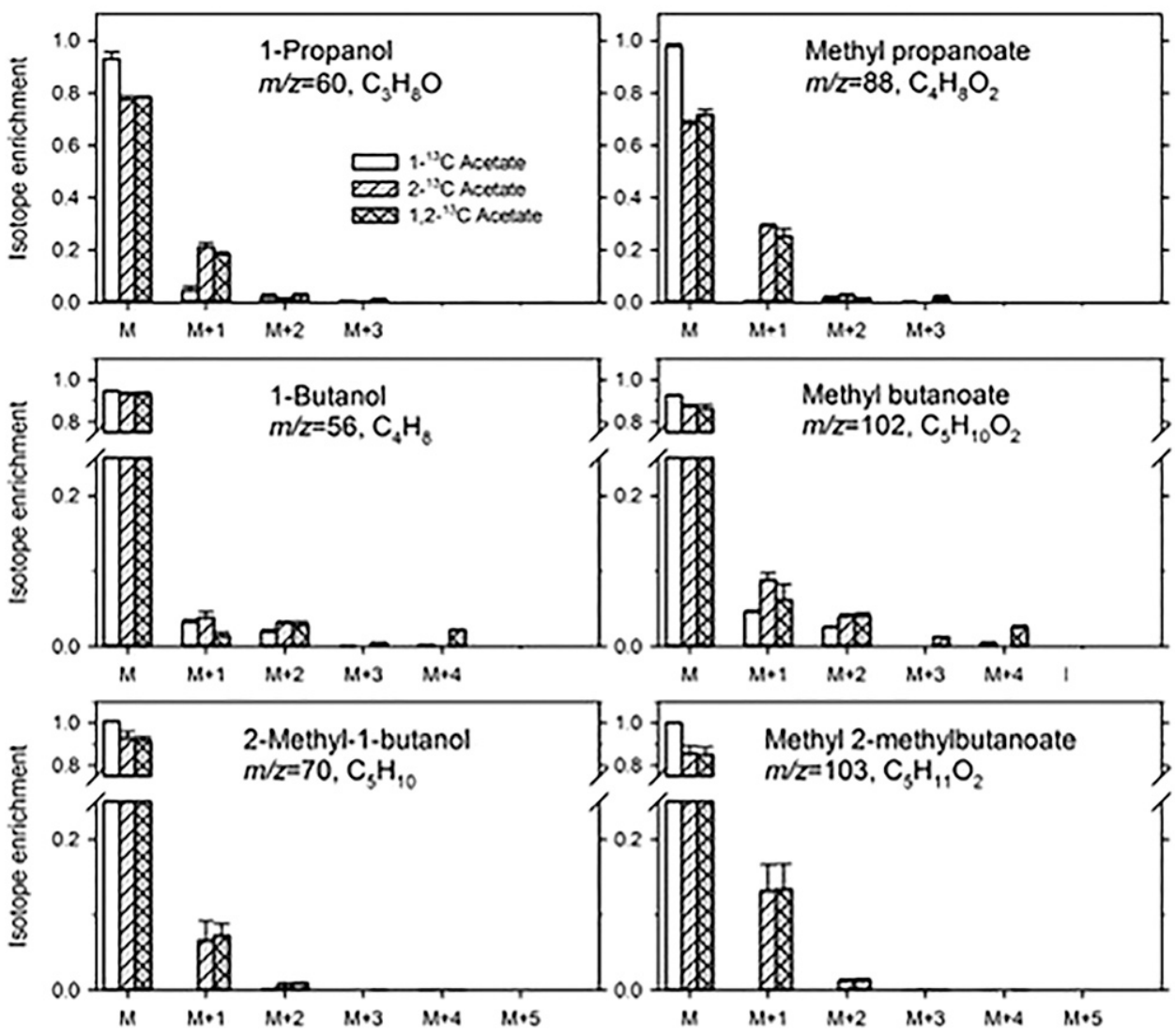

Methyl 2-methylbutanoate
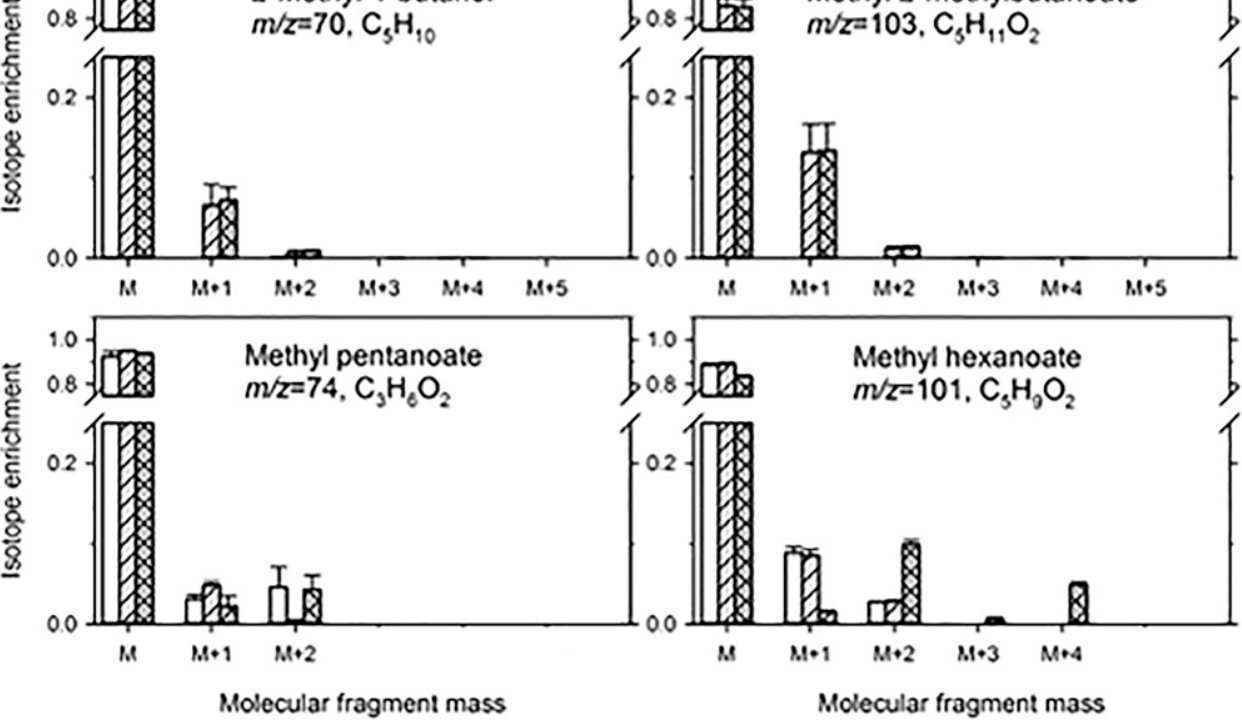

Fig. 22. Mass isotopolog distribution of alcohols and methyl esters during ripening and senescence of 'Redchief Delicious' from apple disks fed with methanol $(\mathrm{MeOH}, 20 \mathrm{~mm})$ and $1-\left[{ }^{13} \mathrm{C}\right]$ acetate, $2-\left[{ }^{13} \mathrm{C}\right]$ acetate, or $1,2-\left[{ }^{13} \mathrm{C}_{2}\right]$ acetate $(20 \mathrm{~mm})$ and incubated at $22{ }^{\circ} \mathrm{C}$ for 5 or $21 \mathrm{~h}$. The isotope distribution (in mole fraction) is expressed as unlabeled mass $(\mathrm{M})$ and up to 5 mass units heavier $(\mathrm{M}+5)$ than the unlabeled compound. There were three biological replicates for each data point. Vertical bars represent the SD of the mean.

The simple semiquantitative approach used here revealed patterns that appeared to reflect known shifts in apple fruit aroma, especially with regard to the development of an overripe aroma. Based on the calculations of predicted aroma impact, ethyl propanoate, ethyl butanoate, ethyl 2-methylbutanoate, and ethyl hexanoate contributed to $\approx 90 \%$ of the perception of an overripe sensation. This is very much in agreement with the work of Dimick and Hoskin (1983) and Willaert et al. (1983) on the impact of these compounds on overripe apple aroma perceptions and appears to partially validate the approach used here. Development of an overripe perception is expected to be primarily due to the extremely low odor thresholds for the four compounds listed, but also due to the increased production of each in the later phases of ripening and senescence. Importantly, given the evident dependence of ester production on the availability of the alkyl moiety shown here, these esters likely result directly from the greater availability of ethanol in ripe and senescent 'Redchief Delicious' fruit. The implication is that if the production of ethanol could be delayed or diminished, the perception of an overripe aroma could be minimized.

Evidence for specific pathways to synthesize ester precursors is sparse, but Sugimoto et al. (2021) recently demonstrated the ripening-dependent induction of a "citramalate pathway" in apple. These researchers linked the ability to synthesize citramalate, a dicarboxylic acid dianion formed from acetyl-CoA and pyruvate, to the formation of ester precursors 2-methyl-1-butanol, 2-methylbutanoate, 1-propanol, and propanoate. The fact that this single pathway is a source for all four of these compounds may explain high correlations between each substrate and its respective ester. The presence of a functional citramalate synthase isozyme is essential for adequate production of 2-methylbutyl, 2-methylbutanoate, propyl and propanoate esters in 

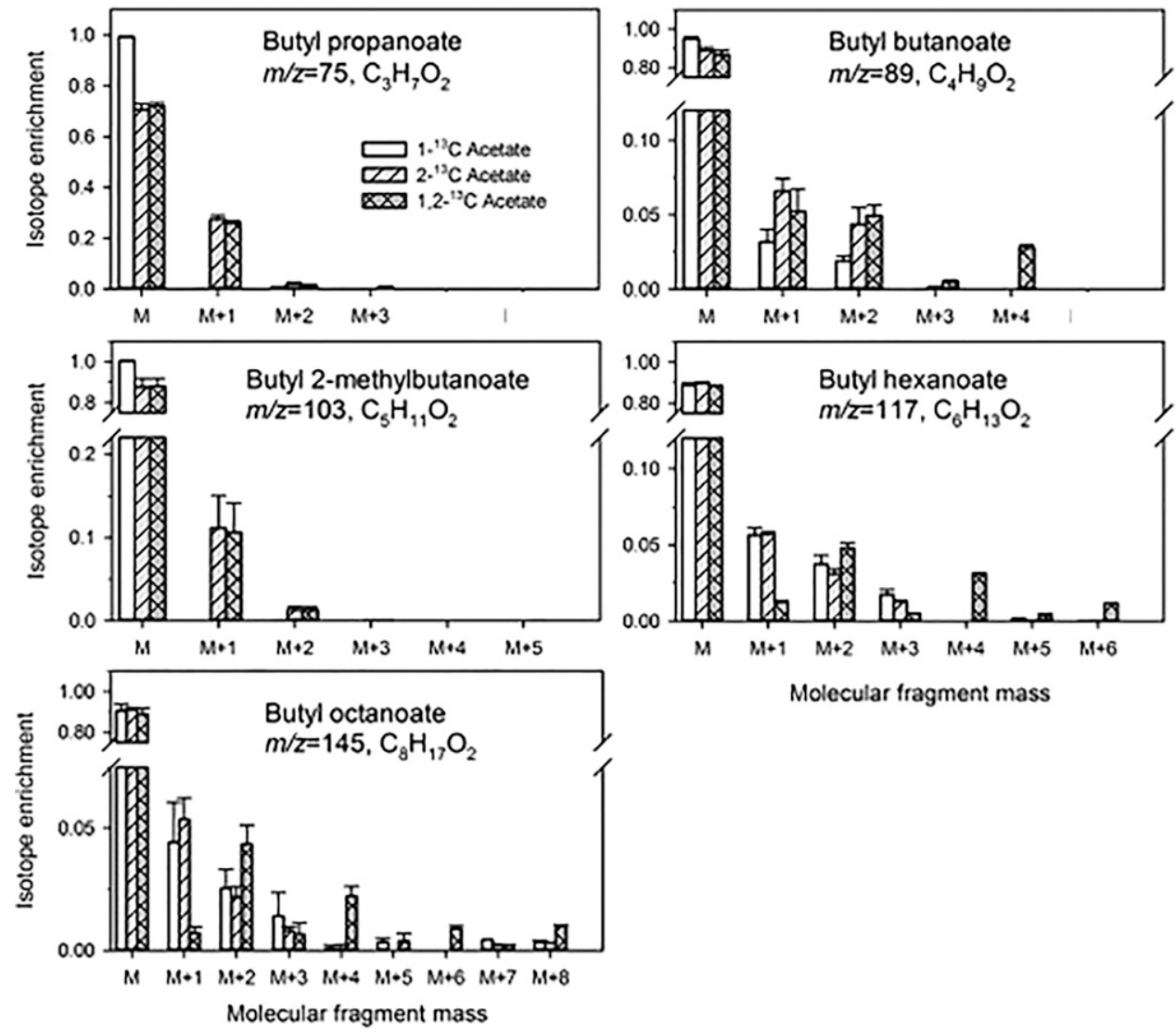

Molecular fragment mass

Fig. 23. Mass isotopolog distribution of butyl esters of 'Redchief Delicious' from ripe apple disks fed with methanol (MeOH, $20 \mathrm{~mm})$ and $1-\left[{ }^{13} \mathrm{C}\right]$ acetate, 2$\left[{ }^{13} \mathrm{C}\right]$ acetate, or $1,2-\left[{ }^{13} \mathrm{C}_{2}\right]$ acetate $(20 \mathrm{~mm})$ and incubated at $22{ }^{\circ} \mathrm{C}$ for 5 or $21 \mathrm{~h}$. The isotope distribution (in mole fraction) is expressed as unlabeled mass $(\mathrm{M})$ and up to 8 mass units heavier $(\mathrm{M}+8)$ than the unlabeled compound. There were three biological replicates for each data point. Vertical bars represent the SD of the mean.

apple (Sugimoto et al., 2021), so it is interesting that the rise in propyl and propanoate esters trailed branched-chain esters, despite being at least partially derived from the same pathway. It is possible that shifting substrate preferences by decarboxylase or AAT isozymes may contribute to this difference (Pérez et al., 1993; Souleyre et al., 2005; Wang et al., 2019; Zhu et al., 2008).

Souleyre et al. (2005) noted that, early in ripening, when the levels of acetyl-CoA and alcohols may be more limiting, MdAAT1 prefers to react with 2-methyl-1-butanol, as its enzymatic efficiency is higher with this substrate than with 1-butanol or 1-hexanol. Thus, they predict that apple would be more likely to synthesize 2-methylbutyl acetate early in ripening, which is consistent with the findings in the current study. Knee and Hatfield (1981) suggested that the supply of alcohols was the primary limiting factor in the formation of acetate esters. They found that the tissue content of 1-butanol increased many-fold as ripening progressed in 'Cox's Orange Pippin', much in keeping with the present study. Their estimates of 1-butanol and 1-hexanol were, respectively, 3- and 30-fold higher than those in this study. This may reflect cultivar differences, but may also reflect the impact of the ventilation in the current study. In as much as the flow through the respirometers was higher than that in the work by Knee and Hatfield (1976), the actual concentration of these alcohols in the tissues of 'Redchief Delicious' fruit is likely higher than the estimates provided. It is presumed that the underestimate would be similar for the three alcohols evaluated given the similarity in their diffusive behavior (National Institute of
Standards and Technology, 2011; Tucker and Nelken, 1982). Nevertheless, the finding by Knee and Hatfield (1976) that 1butanol was substantially more abundant than 1-hexanol in ripening apple is similar to that found here.

The incorporation of ${ }^{13} \mathrm{C}$-acetate into esters and alcohol derivatives of the citramalate pathway has previously only been shown for 'Jonagold' apple fruit (Sugimoto et al., 2021). Consistent with that study, the data here suggest 1-butanol and butanoate are synthesized via mixture of 1-C FAB (via the citramalate pathway) and 2-C FAB. Interestingly, the labeling of the $M+1$ and $M+2$ isotopologs of methyl and butyl hexanoate and butyl octanoate by $1-\left[{ }^{13} \mathrm{C}\right]$ acetate and the $\mathrm{M}+2, \mathrm{M}+4, \mathrm{M}+6$, and $\mathrm{M}+8$ isotopologs of these same esters by $1,2-\left[{ }^{13} \mathrm{C}_{2}\right]$ acetate suggest that longerchain acids possessing an even number of carbons are partly or perhaps entirely derived from another pathway, likely via 2-C FAB (Kroumova and Wagner, 2003). What is not clear, however, is whether these acids are produced directly from this synthetic pathway during chain elongation or are produced from the catabolism of mature lipids that have incorporated ${ }^{13} \mathrm{C}$ acetate (Rowan et al., 1999).

The estimation of an apparent $V_{\max }$ for acetate esters for whole fruit is dependent on acetyl-CoA being nonlimiting and on knowledge of the tissue concentrations of the alcohol substrates. Incorporation of ${ }^{13} \mathrm{C}$ label into the esters of 'Redchief Delicious' demonstrates that the supplied acetate is readily converted to acetyl-CoA and subsequently incorporated into esters as it competes with native acetate for the ester forming reactions. However, the 


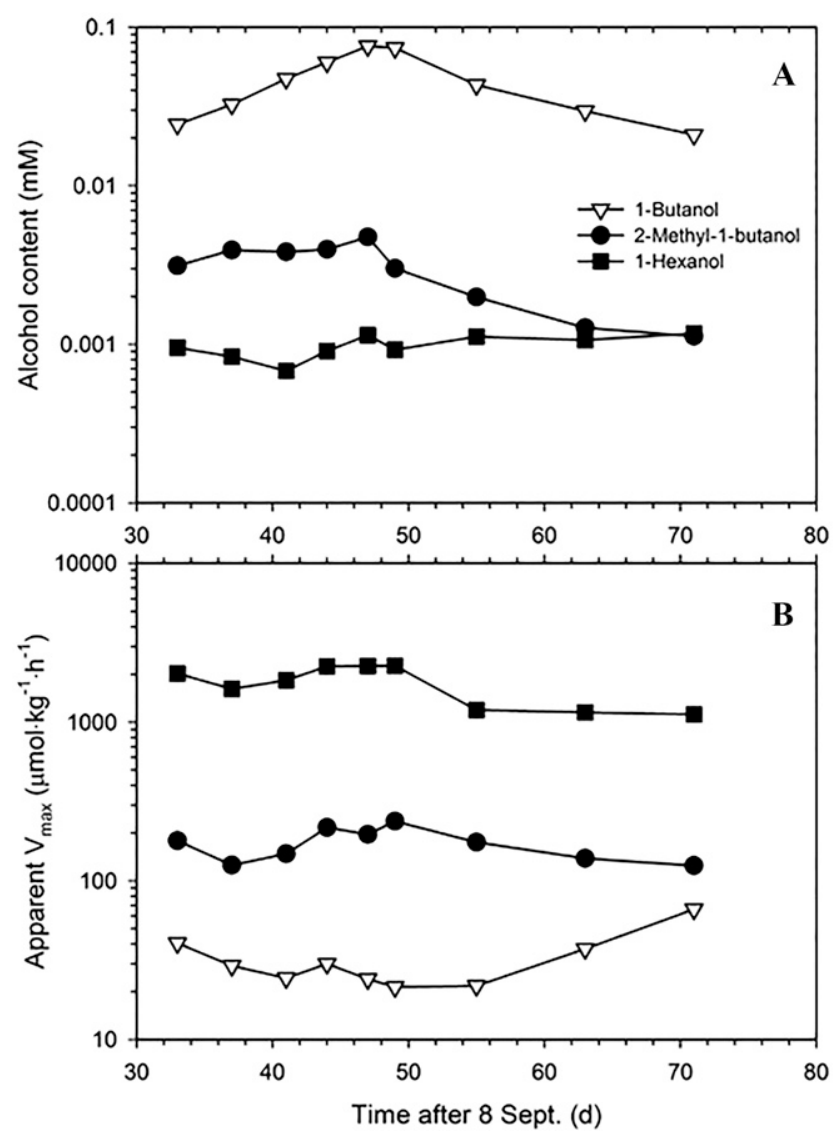

Fig. 24. Tissue alcohol content (A) based on the Henry's coefficient and apparent $\mathrm{V}_{\max }$ for apple AAT reactions when acetyl-CoA was the substrate on a per kilogram fruit basis (B) during ripening and senescence of 'Redchief Delicious' fruit at $20^{\circ} \mathrm{C}$. $\mathrm{V}_{\max }$ values were calculated using the estimated alcohol content, ester production rate, and published $\mathrm{K}_{\mathrm{m}}$ values for MpAAT1 when acetyl-CoA was saturating (Souleyre et al., 2005).

lack of an effect of applied acetate on individual and total acetate ester production (Tables 3 and 4) for ripe fruit implies that the supply of acetyl-CoA to AAT is saturating and therefore allows rough estimation of the apparent $\mathrm{V}_{\max }$ for 1-butanol,2-methyl-1butanol, and 1-hexanol for MdAAT1, for which the $K_{m}$ are known (Souleyre et al., 2005). Estimated tissue concentration of these three alcohols during fruit ripening ranged from $\approx 0.001$ $\mathrm{mm}$ for 1-hexanol to $0.1 \mathrm{~mm}$ for 1-butanol during the period of maximal ester biosynthesis from day 33 to day 71 (Fig. 24A).

The estimates for the apparent $V_{\max }$ for AAT catalyzed reactions using acetyl-CoA had the order 1-hexanol $>2$-methyl-1butanol >1-butanol (Fig. 24B). This is identical to the order determined by enzymatic analysis of MdAAT1 when the cosubstrate was acetyl-CoA by Souleyre et al. (2005), although the magnitude of the differences in the estimates was larger in this study. This may reflect uncertainties in the estimates of the alcohols available to AAT in vivo; whole tissue concentrations would likely not precisely reflect conditions at the site of the reaction. The apparent $\mathrm{V}_{\max }$ for the three alcohols was relatively steady throughout the earlier stages of ripening, but increased for 1-butanol during senescence, which is reflected by an increase in the apparent $\mathrm{V}_{\max }$ for 1-butanol relative to 1-hexanol (Fig. 25). A marked shift in the $\mathrm{V}_{\max }$ for one reaction relative to the others may reflect a shift in the composition of AAT isozymes. In the current work, the apparent $\mathrm{V}_{\max }$ for 1-butanol increasing relative to that for 1-hexanol is

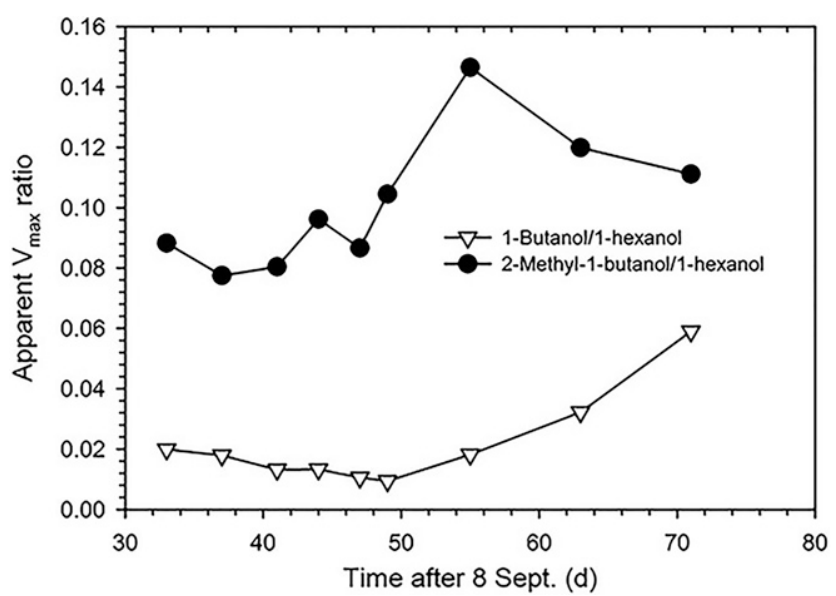

Fig. 25. Ratio of the apparent $V_{\max }$ for 1-butanol to that of 1-hexanol and the ratio of the apparent $V_{\max }$ for 2-methyl-1-butanol to that of 1-hexanol for the formation of their acetate esters via MpAAT1 during ripening and senescence of 'Redchief Delicious' fruit at $20^{\circ} \mathrm{C}$.

consistent with one or more AAT isozymes preferentially expressed at the latter stages of ripening. Zhu et al. (2008) showed that although the expression of $M d A A T 1$ increased early in maturation of 'Golden Delicious' and remained high, MdAAT2 increased only during the latter stages of ripening and senescence. Unfortunately, although Li et al. (2006) documented activity of MdAAT2 with 1butanol, its activity with other substrates was not evaluated, so it is difficult to draw further conclusions on the impact of MdAAT2 on the volatile profile. The lack of enzymatic characterization and extractable activity data for MdAAT2 and the presence of many other MdAAT isozymes limit our ability to fully understand the role of this enzyme family in apple.

In addition to the necessary work on AAT, more research is needed to understand the less explored reactions that support ester formation, such as those that form or interconvert aldehydes, alcohols, and acids via the activities of $\alpha$-ketoacid decarboxylase and dehydrogenase, aldehyde dehydrogenase, acyl-CoA synthetase, acyl-CoA reductase, lipoxygenase, and esterase (Rowan et al., 1996, 1999; Schiller et al., 2015; Wang et al., 2019). Further, the presumably well understood, but little investigated 2-FAB pathway needs to be reassessed as it relates to the biosynthesis of ester precursors in fruit and other specialized plant organs (Sugimoto et al., 2021). There is much yet to be done in this field to link genes, enzymes, physiology, and aroma, and rich opportunities exist for future contributions.

\section{Literature Cited}

Aharoni, A., L.C.P. Keizer, H.J. Bouwmeester, Z.K. Sun, M. Alvarez-Huerta, H.A. Verhoeven, J. Blaas, A.M.M.L. van Houwelingen, R.C.H. De Vos, H. van der Voet, R.C. Jansen, M. Guis, J. Mol, R.W. Davis, M. Schena, A.J. van Tunen, and A.P. O'Connell. 2000. Identification of the SAAT gene involved in strawberry flavor biogenesis by use of DNA microarrays. Plant Cell 12:647-661, doi: https://doi.org/10.1105/tpc.12.5.647.

Bangerth, F., J. Streif, J. Song, and A. Brackmann. 1998. Investigations into the physiology of volatile aroma production of apple fruits. Acta Hort. 464:189-194, doi: https://doi.org/10.17660/ActaHortic.1998.464.26.

Bartelt, R.J. 1997. Calibration of a commercial solid-phase microextraction device for measuring headspace concentrations of organic volatiles. Anal. Chem. 69:364-372, doi: https://doi.org/10.1021/ ac960820n. 
Bartley, I.M., P.G. Stoker, A.D.E. Martin, S.G.S. Hatfield, and M. Knee. 1985. Synthesis of aroma compounds by apples supplied with alcohols and methyl esters of fatty acids. J. Sci. Food Agr. 36:567-574, doi: https://doi.org/10.1002/jsfa.2740360708.

Beekwilder, J., M. Alvarez-Huerta, E. Neef, F.W.A. Verstappen, H.J. Bouwmeester, and A. Aharoni. 2004. Functional characterization of enzymes forming volatile esters from strawberry and banana. Plant Physiol. 135:1865-1878, doi: https://doi.org/10.1104/pp.104.042580.

Berger, R.G. and F. Drawert. 1984. Changes in the composition of volatiles by post-harvest application of alcohols to Red Delicious apples. J. Sci. Food Agr. 35:1318-1325, doi: https://doi.org/10.1002/ jsfa.2740351208.

Biemann, K. 1962. Mass spectrometry: Organic chemical applications. McGraw Hill, New York, NY.

Brackmann, A., J. Streif, and F. Bangerth. 1993. Relationship between a reduced aroma production and lipid metabolism of apples after long-term controlled-atmosphere storage. J. Amer. Soc. Hort. Sci. 118:243-247, doi: https://doi.org/10.21273/JASHS.118.2.243.

Brown, D.S., J.R. Buchanan, and J.R. Hicks. 1966. Volatiles from apple fruits as related to variety, maturity, and ripeness. Proc. Amer. Soc. Hort. Sci. 88:98-104.

Chambers, E., IV and K. Koppel. 2013. Associations of volatile compounds with sensory aroma and flavor: The complex nature of flavor. Molecules 18:4887-4905, doi: https://doi.org/10.3390/molecules 18054887

Contreras, C. and R.M. Beaudry. 2013. Lipoxygenase-associated apple volatiles and their relationship with aroma perception during ripening. Postharvest Biol. Technol. 82:28-38, doi: https://doi.org/ 10.1016/j.postharvbio.2013.02.006.

Contreras, C., H. Tjellström, and R.M. Beaudry. 2015. Relationships between free and esterified fatty acids and LOX-derived volatiles during ripening in apple. Postharvest Biol. Technol. 112:105-113, doi: https://doi.org/10.1016/j.postharvbio.2015.10.009.

Cumplido-Laso, G., L. Medina-Puche, E. Moyano, T. Hoffmann, Q. Sinz, L. Ring, C. Studart-Wittkowski, J.L. Caballero, W. Schwab, J. Muñoz-Blanco, and R. Blanco-Portales. 2012. The fruit ripeningrelated gene FaAAT2 encodes an acyl transferase involved in strawberry aroma biogenesis. J. Expt. Bot. 63:4275-4290, doi: https://doi. org/10.1093/jxb/ers120.

Defilippi, B., A.A. Kader, and A.M. Dandekar. 2005. Apple aroma: Alcohol acyltransferase, a rate limiting step for ester biosynthesis, is regulated by ethylene. Plant Sci. 168:1199-1210, doi: https://doi.org/ 10.1016/j.plantsci.2004.12.018.

De Pooter, H.L., J.P. Montens, G.A. Willaert, P.J. Dirinck, and N.M. Schamp. 1983. Treatment of golden delicious apples with aldehydes and carboxylic acids: Effect on the headspace composition. J. Agr. Food Chem. 31:813-818, doi: https://doi.org/10.1021/jf00118a034.

Dimick, P.S. and J.C. Hoskin. 1983. Review of apple flavor - State of the art. CRC Crit. Rev. Food Sci. Nutr. 18:387-409.

Dirinck, P., H. De Pooter, and N. Schamp. 1989. Aroma development in ripening fruits, p. 24-34. In: R. Teranishi, R.G. Buttery, and F. Shahidi (eds.). Flavor chemistry: Trends and developments. ACS Symp. Ser. 388. Amer. Chem. Soc., Washington, DC.

Dixon, J. and E.W. Hewett. 2000a. Exposure to hypoxia conditions alters volatile concentrations of apple cultivars. J. Sci. Food Agr. 81:22-29, doi: https://doi.org/10.1002/1097-0010(20010101)81:1<22: AID-JSFA769>3.0.CO;2-9.

Dixon, J. and E.W. Hewett. 2000b. Factors affecting apple aroma/flavour volatile concentration: A review. N. Z. J. Crop Hort. Sci. 28:155-173, doi: https://doi.org/10.1080/01140671.2000.9514136.

Drawert, F., W. Heimann, R. Emberger, and R. Tressl. 1969. Über die biogenese yon aromastoffen bei pflanzen und friichten. IV. Mitteilung. Bildung der aromastoffe des apfels im verlauf des wachstums and bei der lagerung. Z. Lebensmitel-Untersueh. u. Forsch. 140:65-88.

Dunemann, F., D. Ulrich, L. Malysheva-Otto, W.E. Weber, S. Longhi, R. Velasco, and F. Costa. 2012. Functional allelic diversity of the apple alcohol acyl-transferase gene MdAAT1 associated with fruit ester volatile contents in apple cultivars. Mol. Breed. 29:609-625, doi: https://doi.org/10.1007/s11032011-9577-7.

Espino-Díaz, D.R.S., G. González-Aguilar, and G.I. Olivas. 2016. Biochemistry of apple aroma: A review. Food Technol. Biotechnol. 54:375-394, doi: https://doi.org/10.17113/ftb.54.04.16.4248.

Fan, X.T., J.P. Mattheis, and D. Buchanan. 1998. Continuous requirement of ethylene for apple fruit volatile synthesis. J. Agr. Food Chem. 46:1959-1963, doi: https://doi.org/10.1021/jf970877q.

Fellman, J.K. and J.P. Mattheis. 1995. Ester biosynthesis in relation to harvest maturity and controlled-atmosphere storage of apples, $\mathrm{p}$. 149-162. In: R.L. Rouseff and M.M. Leahy (eds.). Fruit flavors: Biogenesis, characterization, and authentication. ACS Symp. Ser. 596. Amer. Chem. Soc., Washington, DC.

Fellman, J.K., D.S. Mattinson, B.C. Bostick, J.P. Mattheis, and M.E. Patterson. 1993. Ester biosynthesis in 'Rome' apples subjected to low-oxygen atmospheres. Postharvest Biol. Technol. 3:201-214, doi: https://doi.org/10.1016/0925-5214(93)90056-9.

Fellman, J.K., T.W. Miller, and D.S. Mattinson. 2000. Factors that influence biosynthesis of volatiles flavor compounds in apple fruit. HortScience 35:1026-1033, doi: https://doi.org/10.21273/HORTSCI. 32.3.554C.

Ferenczi, A., J. Song, M. Tian, K. Vlachonasios, D. Dilley, and R. Beaudry. 2006. Volatile ester suppression and recovery following 1methylcyclopropene application to apple fruit. J. Amer. Soc. Hort. Sci. 131:691-701, doi: https://doi.org/10.21273/JASHS.131.5.691.

Flath, R.A., D.R. Black, D.G. Guadagni, W.H. McFadden, and T.H. Schultz. 1967. Identification and organoleptic evaluation of compounds in Delicious apple essence. J. Agr. Food Chem. 15:29-35, doi: https://doi.org/10.1021/jf60149a032.

Harada, M., Y. Ueda, and T. Iwata. 1985. Purification and some properties of alcohol acetyltransferase from banana fruit. Plant Cell Physiol. 26:1067-1074, doi: https://doi.org/10.1093/oxfordjournals.pcp. a077002.

Jayanty, S., J. Song, N.M. Rubinstein, A. Chong, and R.M. Beaudry. 2002. Temporal relationship between ester biosynthesis and ripening events in bananas. J. Amer. Soc. Hort. Sci. 127:998-1005, doi: https://doi.org/10.21273/JASHS.127.6.998.

Kakiguchi, N., S. Moriguchi, H. Fukuda, N. Ichimura, Y. Kato, and Y. Banba. 1986. Composition of volatile compounds of apple fruits in relation to cultivar. J. Jpn. Soc. Hort. Sci. 55:280-289, doi: https:// doi.org/10.2503/jjshs.55.280.

Knee, M. 1991. Rapid measurement of diffusion of gas through the skin of apple fruits. HortScience 26:885-887, doi: https://doi.org/ 10.21273/HORTSCI.26.7.885.

Knee, M. and S.G.S. Hatfield. 1976. A comparison of methods for measuring the volatile components of apple fruits. J. Food Technol. 11:485-493.

Knee, M. and S.G.S. Hatfield. 1981. The metabolism of alcohols by apple fruit tissue. J. Sci. Food Agr. 32:593-600, doi: https://doi.org/ 10.1111/j.1365-2621.1976.tb00748.x.

Kroumova, A.B. and G.J. Wagner. 2003. Different elongation pathways in the biosynthesis of acyl groups of trichome exudate sugar esters from various solanaceous plants. Planta 216:1013-1021, doi: https://doi.org/10.1007/s00425-002-0954-7.

Leffingwell and Associates. 2021. Odor thresholds. Odor \& flavor detection thresholds in water (in parts per billion). 3 Apr. 2021. $<$ http://www.leffingwell.com/odorthre.htm $>$.

Li, D., Y. Xu, G. Xu, L. Gu, D. Li, and H. Shu. 2006. Molecular cloning and expression of a gene encoding alcohol acyltransferase (MdAAT2) from apple (cv. Golden Delicious). Phytochemistry 67:658-667, doi: https://doi.org/10.1016/j.phytochem.2006.01.027.

Mattheis, J.P., J.K. Fellman, P.M. Chen, and M.E. Patterson. 1991. Changes in headspace volatiles during physiological development of Bisbee Delicious apple fruit. J. Agr. Food Chem. 39:1902-1906, doi: https://doi.org/10.1021/jf00011a002.

Mattheis, J.P., D.A. Buchanan, and J.K. Fellman. 1995. Volatile compound production by Bisbee Delicious apples after sequential atmosphere storage. J. Agr. Food Chem. 43:194-199. 
Miller, T.W., J.K. Fellman, J.P. Mattheis, and D.S. Mattinson. 1998. Factors that influence volatile ester biosynthesis in 'Delicious' apples. Acta Hort. 464:195-200, doi: https://doi.org/10.1021/jf000 49a036.

Mir, N. and R.M. Beaudry. 1999. Effect of superficial scald suppression by diphenylamine application on volatile aroma biosynthesis. J. Agr. Food Chem. 47:7-11, doi: https://doi.org/10.1021/ jf9805810.

Mir, N.A., E. Curell, N. Khan, M. Whitaker, and R.M. Beaudry. 2001. Harvest maturity, storage temperature, and 1-MCP application frequency alter firmness retention and chlorophyll fluorescence of 'Redchief Delicious' apples. J. Amer. Soc. Hort. Sci. 126:618-624, doi: https://doi.org/10.21273/JASHS.126.5.618.

Murphy, C., W.S. Cain, and L.M. Bartoshuk. 1977. Mutual action of taste and olfaction. Sens. Processes 1:204-211, doi: https://oi.org/ 10.1111/j.1749-6632.1987.tb43471.x.

National Institute of Standards and Technology. 2011. Chemistry webBook. 1 Mar. 2021. <http://webbook.nist.gov/chemistry/name-ser.html >.

Nursten, H.E. 1970. Volatile compounds: The aroma of fruits, p. 239-265. In: A.C. Hulme (ed.). The biochemistry of fruits and their products. Vol. 1. Academic Press, New York, NY.

Olias, J.M., C. Sanz, J.J. Rios, and A.G. Pérez. 1995. Substrate specificity of alcohol acyltransferase from strawberry and banana fruits, $p$. 134-141. In: R.L. Rouseff and M.M. Leahy (eds.). Fruit flavors: Biogenesis, characterization, and authentication. ACS Symp. Ser. 596. Amer. Chem. Soc., Washington, DC.

Patterson, B.D., S.G.S. Hatfield, and M. Knee. 1974. Residual effects of controlled atmosphere storage on the production of volatile compounds by two cultivars of apples. J. Food Sci. Agr. 25:843-849, doi: https://doi.org/10.1002/jsfa.2740250714.

Pérez, A.G., C. Sanz, and J.M. Olias. 1993. Partial purification and some properties of alcohol acyltransferase from strawberry fruits. J. Agr. Food Chem. 41:1462-1466, doi: https://doi.org/10.1021/jf00033a021.

Pérez, A.G., C. Sanz, R. Olias, J.J. Rios, and J.M. Olias. 1996. Evolution of strawberry alcohol acyltransferase activity during fruit development and storage. J. Agr. Food Chem. 44:3286-3290, doi: https:// doi.org/10.1021/jf960040f.

Pérez, A.G., R. Olías, P. Luaces, and C. Sanz. 2002. Biosynthesis of strawberry aroma compounds through amino acid metabolism. J. Agr. Food Chem. 50:4037-4042, doi: https://doi.org/10.1021/jf011465r.

Risso, C., S.J. Van Dien, A. Orloff, D.R. Lovley, and M.V. Coppi. 2008. Elucidation of an alternate isoleucine biosynthesis pathway in Geobacter sulfurreducens. J. Bacteriol. 190:2266-2274, doi: https:// doi.org/10.1128/JB.01841-07.

Rowan, D.D., H.P. Lane, J.M. Allen, S. Fielder, and M.B. Hunt. 1996. Biosynthesis of 2-methylbutyl, 2-methyl-2-butenyl, and 2-methylbutanoate esters in Red Delicious and Granny Smith apples using deuterium-labeled substrates. J. Agr. Food Chem. 44:3276-3285, doi: https://doi.org/10.1021/jf9508209.

Rowan, D.D., J.M. Allen, S. Fielder, and M.B. Hunt. 1999. Biosynthesis of straight-chain ester volatiles in 'Red Delicious' and 'Granny Smith' apples using deuterium-labeled precursors. J. Agr. Food Chem. 47:2553-2562, doi: https://doi.org/10.1021/jf9809028.

Sander, R. 2015. Compilation of Henry's law constants (version 4.0) for water as solvent. Atmos. Chem. Phys. 15:4399-4981. 1 Mar. 2021. <https://acp.copernicus.org/articles/15/4399/2015/>.

Schafer, R.J., E.N. Friel, E.J.F. Souleyre, K. Bolitho, K.T. Hodey, S. Ledger, J.H. Bowen, J.-H. Ma, B. Nain, D. Cohen, A.P. Gleave, R.N. Crowhurst, B.J. Janssen, J.-L. Yao, and R.D. Newcomb. 2007. A genomics approach reveals that aroma production in apple is controlled by ethylene predominantly at the final step in each biosynthetic pathway. Plant Physiol. 144:1899-1912, doi: https://doi.org/ 10.1104/pp.106.093765.

Schiller, D., C. Contreras, J. Vogt, F. Dunemann, B. Defilippi, R. Beaudry, and W. Schwab. 2015. A dual positional specific lipoxygenase functions in the generation of flavor compounds during climacteric ripening of apple. Hort. Res. (Nature) 2:15003, doi: https://doi.org/10.1038/hortres.2015.3.

Song, J. and F. Bangerth. 1994. Production and development of volatile aroma compounds of apple fruits at different times of maturity. Acta Hort. 368:150-159, doi: https://doi.org/10.17660/ActaHortic.1994.368.16.

Song, J. and F. Bangerth. 1996. The effect of harvest date on aroma compound production from 'Golden Delicious' apple fruit and relationship to respiration and ethylene production. Postharvest Biol. Technol. 8:259-269, doi: https://doi.org/10.1016/0925-5214(96) 00020-8.

Song, J., B.D. Gardner, J.F. Holland, and R.M. Beaudry. 1997. Rapid analysis of volatile flavor compounds in apple fruit using SPME and GC/time-of-flight mass spectrometry. J. Agr. Food Chem. 45:1801-1807, doi: https://doi.org/10.1021/jf9608229.

Souleyre, E.J.F., D.R. Greenwood, E.N. Friel, S. Karunairetnam, and R.D. Newcomb. 2005. An alcohol acyl transferase from apple (cv. Royal Gala), MpAAT1, produces esters involved in apple fruit flavor. FEBS J. 272:3132-3144, doi: https://doi.org/10.1111/j.17424658.2005.04732.x.

Sugimoto, N., A.D. Jones, and R. Beaudry. 2011. Changes in free amino acid content in 'Jonagold' apple fruit as related to branchedchain ester production, ripening, and senescence. J. Amer. Soc. Hort. Sci. 136:429-440, doi: https://doi.org/10.21273/JASHS.136.6.429.

Sugimoto, N., P. Forsline, and R. Beaudry. 2015. Volatile profiles of members of the USDA Geneva Malus core collection: Utility in evaluation of a hypothesized biosynthetic pathway for esters derived from 2-methylbutanoate and 2-methylbutanol. J. Agr. Food Chem. 63:2106-2116, doi: https://doi.org/10.1021/jf505523m.

Sugimoto, N., P. Engelgau, A.D. Jones, J. Song, and R.M. Beaudry. 2021. Citramalate synthase yields a novel plant pathway for the synthesis of isoleucine and straight- and branched-chain esters in apple. Proc. Natl. Acad. Sci. USA 118:e2009988118, doi: https://doi.org/ 10.1073/pnas.2009988118.

Tan, T. and F. Bangerth. 2001. Are adenine and/or pyridine nucleotides involved in the volatile production of prematurely harvested or long term ULO stored apple fruits? Acta Hort. 553:215-218, doi: https://doi.org/10.17660/ActaHortic.2001.553.47.

The Good Scents Company. 2021. TGSC Information system. 3 Apr. 2021. $<$ http://www.thegoodscentscompany.com/data/rw1004792.html $>$.

Tucker, W.A. and L.H. Nelken. 1982. Diffusion coefficients in air and water, p. 17/1-17/25. In: W.J. Lyman, W.F. Reehl, and D.H. Rosenblatt (eds.). Handbook of chemical property estimation methods. Amer. Chem. Soc., Washington, DC.

Tressl, R. and F. Drawert. 1973. Biogenesis of banana volatiles. J. Agr. Food Chem. 21:560-565, doi: https://doi.org/10.1021/jf60188a031.

Ueda, Y. and K. Ogata. 1977. Coenzyme A-dependent esterification of alcohols and acids in separated cells of banana pulp and its homogenate. Nippon Shokuhin Kogyo Gakkaishi 24:624-630.

Vanoli, M., C. Visai, and A. Rizzolo. 1995. The influence of harvest date on the volatile composition of 'Starkspur-Golden' apples. Postharvest Biol. Technol. 6:225-234, doi: https://doi.org/10.1016/09255214(95)00012-U.

Wang, M., L. Zhang, K.H. Boo, E. Park, G. Drakakaki, and F. Zakharov. 2019. PDC1, a pyruvate/ $\alpha$-ketoacid decarboxylase, is involved in acetaldehyde, propanol and pentanal biosynthesis in melon (Cucumis melo L.) fruit. Plant J. 98:112-125, doi: https://doi. org/10.1111/tpj.14204.

Willaert, G.A., P.J. Dirinck, H.L. De Pooter, and N.N. Schamp. 1983. Objective measurement of aroma quality of Golden Delicious apples as a function of controlled atmosphere storage time. J. Agr. Food Chem. 31:809-813, doi: https://doi.org/10.1021/jf00118a033.

Williams, A.A. and M. Knee. 1977. The flavour of Cox's Orange Pippin apples and its variation with storage. Ann. Appl. Biol. 87:127-131, doi: https://doi.org/10.1111/j.1744-7348.1977.tb00670.x. Wyllie, S.G., D.N. Leach, Y. Wang, and R.L. Shewfelt. 1995. Key aroma compounds in melons, p. 248-257. In: R.L. Rouseff and M.M. 
Leahy (eds.). Fruit flavors: Biogenesis, characterization, and authentication. ACS Symp. Ser. 596. Amer. Chem. Soc., Washington, DC.

Wyllie, S.G. and J.K. Fellman. 2000. Formation of volatile branched chain esters in bananas (Musa sapientum L.). J. Agr. Food Chem. 48:3493-3496, doi: https://doi.org/10.1021/jf0001841.

Xu, H., Y. Zhang, X. Guo, S. Ren, A.A. Staempfli, J. Chiao, W. Jiang, and G. Zhao. 2004. Isoleucine biosynthesis in Leptospira interrogans serotype lai strain 56601 proceeds via a threonine-independent pathway. J. Bacteriol. 186:5400-5409, doi: https://doi.org/10.1128/JB. 186.16.5400-5409.2004.

Yahyaoui, F.E., C. Wongs-Aree, A. Latch'e, R. Hackett, D. Grierson, and J.C. Pech. 2002. Molecular and biochemical characteristics of a gene encoding an alcohol acyl-transferase involved in the generation of aroma volatile esters during melon ripening. Eur. J. Biochem. 269:2359-2366, doi: https://doi.org/10.1046/j.1432-1033.2002.02892.x.

Yan, D., J. Shi, X. Ren, Y. Tao, F. Ma, R. Li, X. Liu, and C. Liu. 2020. Insights into the aroma profiles and characteristic aroma of 'Honeycrisp' apple (Malus $\times$ domestica). Food Chem. 327:127074, doi: https://doi.org/10.1016/j.foodchem.2020.127074.

Zhu, Y., D.R. Rudell, and J.P. Mattheis. 2008. Characterization of cultivar differences in alcohol acyltransferase and 1-aminocyclopropane1-carboxylate synthase gene expression and volatile ester emission during apple fruit maturation and ripening. Postharvest Biol. Technol. 49:330-339, doi: https://doi.org/10.1016/j.postharvbio.2008.03.015. 


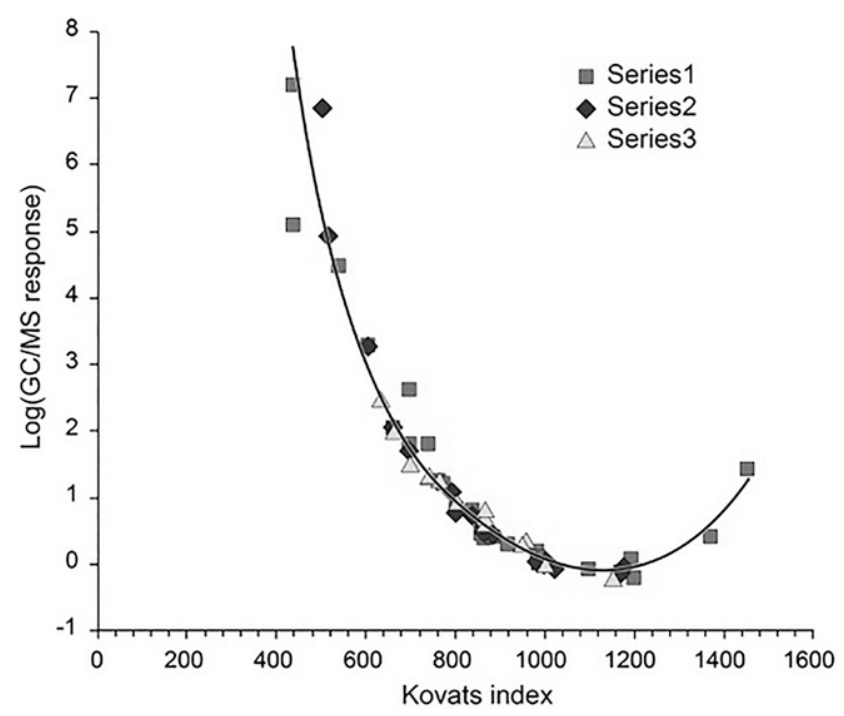

Supplemental Fig. 1. Relationship between Kovats index and instrument response (total ion count) for three series of volatile standard mixes using solid-phase microextraction (SPME) sampling and analysis by gas chromatography/mass spectrometry (GC/MS). Because the concentrations of the standard mixes differed in concentration, the GC/MS response data were normalized using hexyl acetate as a common constituent. 
Supplemental Table 1. Volatile compounds (esters, alcohols, and acids) identified in 'Redchief Delicious' apple fruit during ripening and senescence and associated gas chromatography retention time (RT) in seconds, mass to charge $(\mathrm{m} / \mathrm{z})$ ratio of the unique ion used for quantitation, correction factor, and Kovats index. Each compound was quantified by integrating extracted ion chromatogram peaks for the fragment ions $\mathrm{m} / \mathrm{z}$. Correction factor is used to calculate the total ion count (TIC) from the fractional response of the unique ion. Each TIC value is the result of multiplying the ion count for the unique ion by the correction factor. Where no standard was available, the Kovats index (National Institute of Standards and Technology, 2011) for the compound of interest was used to quantify volatiles by estimation of the instrument response factor (Bartelt, 1997). The Kovats index was dependent on RT according to the following equation: $\mathrm{K}=4.76 \times$ $\mathrm{RT}+255, r^{2}=0.997$. At the time of the experiment, only a limited number of authenticated compounds were available (shown in bold) and these were used in a standard mix throughout the experiment. Compounds with an asterisk were included in standards run following the experimental period and by virtue of their response relative to the standards used at the time of the experiment, were used to identify and quantify additional compounds. These compounds were used to develop a relationship between the Kovats number and response factor (ppm/TIC). Thus, for the remaining compounds, for which no standard was available, quantification was possible using the Kovats relationship with instrument response (Supplemental Fig. 1).

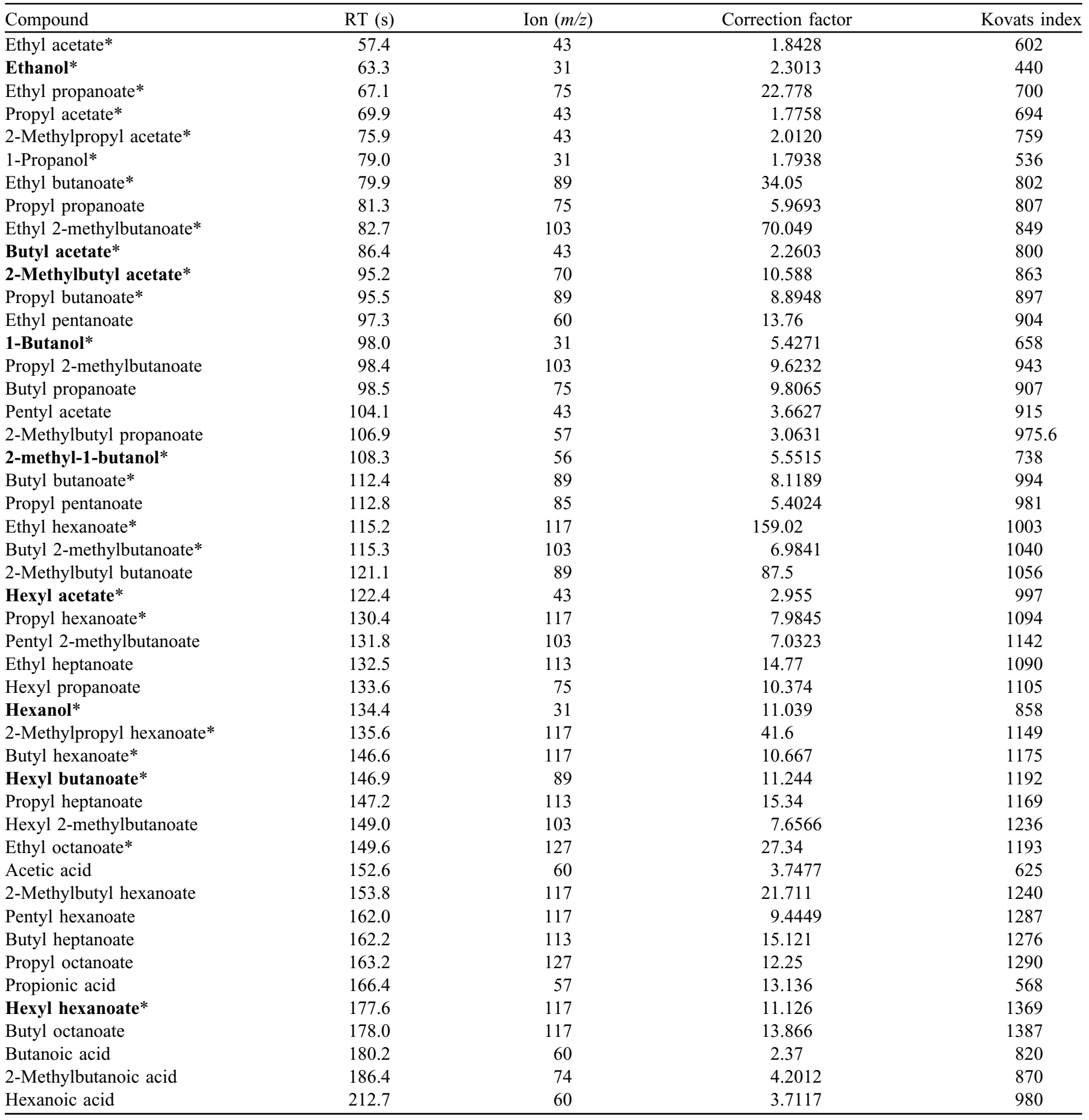


Supplemental Table 2. Analytes and fragment ions $(\mathrm{m} / \mathrm{z})$ evaluated for ${ }^{13} \mathrm{C}$-acetate feeding studies. Volatiles were quantified by integrating extracted ion chromatogram peaks for the molecular ions $\mathrm{m} / z$. Hydrogens are omitted for formulas for analyte molecules. Fragment shown constitutes the portion of molecular formula for mass isotopolog analysis.

\begin{tabular}{|c|c|c|c|}
\hline Analyte & Fragment ion $(\mathrm{m} / \mathrm{z})$ & Fragment formula & $\begin{array}{l}\text { Molecular formula of analyte. } \\
\text { Portion in bold was the source } \\
\text { of the quantified fragment ion. } \\
\text { Hydrogen atoms are not } \\
\text { depicted. }\end{array}$ \\
\hline 1-propanol & 60 & $\mathrm{C}_{3} \mathrm{H}_{8} \mathrm{O}$ & O-C-C-C \\
\hline 1-butanol & 56 & $\mathrm{C}_{4} \mathrm{H}_{8}$ & O-C-C-C-C \\
\hline 2-methyl-1-butanol & 70 & $\mathrm{C}_{5} \mathrm{H}_{10}$ & $\begin{array}{c}\text { O-C-C-C-C } \\
\mid \\
\mathbf{C}\end{array}$ \\
\hline methyl propanoate & 88 & $\mathrm{C}_{4} \mathrm{H}_{8} \mathrm{O}_{2}$ & $\begin{array}{c}\mathrm{C}-\mathrm{O}-\mathrm{C}-\mathrm{C}-\mathrm{C} \\
|| \\
\mathbf{O}\end{array}$ \\
\hline methyl butanoate & 102 & $\mathrm{C}_{5} \mathrm{H}_{10} \mathrm{O}_{2}$ & $\begin{array}{c}\mathrm{C}-\mathrm{O}-\mathrm{C}-\mathrm{C}-\mathrm{C}-\mathrm{C} \\
|| \\
0\end{array}$ \\
\hline methyl 2-methylbutanoate & 102 & $\mathrm{C}_{5} \mathrm{H}_{10} \mathrm{O}_{2}$ & $\begin{array}{c}\text { C-O-C-C-C-C } \\
|| \mid \\
\text { O C }\end{array}$ \\
\hline methyl pentanoate & 74 & $\mathrm{C}_{3} \mathrm{H}_{6} \mathrm{O}_{2}$ & $\begin{array}{c}\text { C-O-C-C-C-C-C } \\
|| \\
0\end{array}$ \\
\hline methyl hexanoate & 101 & $\mathrm{C}_{5} \mathrm{H}_{9} \mathrm{O}_{2}$ & $\begin{array}{c}\text { C-O-C-C-C-C-C-C } \\
|| \\
0\end{array}$ \\
\hline butyl propanoate & 75 & $\mathrm{C}_{3} \mathrm{H}_{7} \mathrm{O}_{2}$ & $\begin{array}{c}\mathrm{C}-\mathrm{C}-\mathrm{C}-\mathrm{C}-\mathrm{O}-\mathbf{C}-\mathbf{C}-\mathbf{C} \\
|| \\
\mathbf{O}\end{array}$ \\
\hline butyl butanoate & 89 & $\mathrm{C}_{4} \mathrm{H}_{9} \mathrm{O}_{2}$ & $\begin{array}{c}\mathrm{C}-\mathrm{C}-\mathrm{C}-\mathrm{C}-\mathrm{O}-\mathrm{C}-\mathrm{C}-\mathrm{C}-\mathrm{C} \\
|| \\
\mathbf{O}\end{array}$ \\
\hline butyl 2-methylbutanoate & 103 & $\mathrm{C}_{5} \mathrm{H}_{11} \mathrm{O}_{2}$ & $\begin{array}{c}\mathrm{C}-\mathrm{C}-\mathrm{C}-\mathrm{C}-\mathrm{O}-\mathrm{C}-\mathrm{C}-\mathrm{C}-\mathrm{C} \\
|| \mid \\
\text { O C }\end{array}$ \\
\hline butyl hexanoate & 117 & $\mathrm{C}_{6} \mathrm{H}_{13} \mathrm{O}_{2}$ & $\begin{array}{c}\text { C-C-C-C-O-C-C-C-C-C-C } \\
|| \\
0\end{array}$ \\
\hline butyl octanoate & 145 & $\mathrm{C}_{8} \mathrm{H}_{17} \mathrm{O}_{2}$ & $\begin{array}{c}\text { C-C-C-C-O-C-C-C-C-C-C-C-C} \\
|| \\
0\end{array}$ \\
\hline
\end{tabular}

